\title{
Two-dimensional infrared correlation spectroscopy studies on secondary structures and hydrogen bondings of side chains of proteins
}

\author{
Yukihiro Ozaki ${ }^{\mathrm{a}, *}$, Koichi Murayama ${ }^{\mathrm{b}}$, Yuqing $\mathrm{Wu}^{\mathrm{c}}$ and Bogusława Czarnik-Matusewicz ${ }^{\mathrm{d}}$ \\ ${ }^{a}$ Department of Chemistry, School of Science and Technology, Kwansei-Gakuin University, \\ Sanda 669-1337, Japan \\ ${ }^{\mathrm{b}}$ Department of Biochemistry and Biophysics, Gifu University School of Medicine, \\ Gifu 500-8705, Japan \\ ${ }^{\mathrm{c}}$ Key Laboratory for Supramolecular Structure and Materials of the Ministry of Education, \\ Jilin University, Changchun, 130023, China \\ ${ }^{\mathrm{d}}$ Faculty of Chemistry, University of Wroctaw, F. Joliot-Curie 14, PL-50-383, Wroctaw, Poland
}

\begin{abstract}
This review paper reports usefulness of two-dimensional (2D) correlation spectroscopy in analyzing infrared (IR) spectra of proteins in aqueous solutions. In the 2D approach, spectral peaks are spread over the second dimension, thereby simplifying the visualization of complex spectra consisting of many overlapped bands, and enhancing spectral resolution. 2D correlation spectroscopy has a powerful deconvolution ability for highly overlapped amide I, amide II, and amide III bands of proteins, enabling these bands to be assigned to various secondary structures. It also provides the specific order of the spectral intensity changes taking place during the measurement on the value of controlling variable affecting the spectra. Therefore, one can monitor the order of secondary structure variations in proteins by using 2D IR correlation spectroscopy. 2D correlation spectroscopy also provides new insight into the hydrogen bondings of side chains of proteins. In this review the principles and advantages of 2D correlation spectroscopy are outlined first and then three examples of the applications of 2D IR spectroscopy to protein research are presented.
\end{abstract}

\section{Introduction}

Infrared (IR) spectroscopy has long been used as a powerful method for investigating the secondary structures of proteins and their dynamics. One of the significant advantages of IR spectroscopy for the studies of proteins is that spectra of proteins with a high signal-to-noise ratio can be obtained easily under various conditions irrespective of the size of proteins [1-16]. One can measure IR spectra of proteins in aqueous solutions, crystals, solids, and even in the presence of other biomolecules. In the IR region, the frequencies of bands due to the amide I, II, and III vibrations are sensitive to the secondary structure of proteins, Particularly, the amide I band is useful for the secondary structure studies. In general, the amide bands consist of several component bands assignable to different secondary structures. Therefore, many attempts have been made to assign the components of the amide bands to secondary structure elements such as $\alpha$-helix and $\beta$-sheet. Usually, second derivative, Fourier self deconvolution (FSD) and curve

\footnotetext{
*Corresponding author. E-mail: ozaki@kwansei.ac.jp
} 
fitting are used to deconvolute the amide bands. However, the results obtained by the above methods are not always conclusive, especially for complex proteins consisting of various secondary structures.

IR spectroscopy is useful also for investigating the hydrogen bonds of side chains of proteins. However, information about the side chains obtained from IR spectra of proteins is still limited [15,16].

The purpose of this review article is to demonstrate potential of generalized two-dimensional (2D) IR correlation spectroscopy [17-25] in protein research. The 2D IR correlation spectroscopy has four major advantages in investigating protein structures [26-40]. One is that the 2D correlation spectroscopy deconvolutes amide bands into component bands due to different secondary structures. Another is that it enables one to establish the correlations between bands due to different secondary structures of protein through selective correlation peaks for given perturbation. Yet another is that one can monitor intensity variations even in very weak protein bands such as those due to the $\mathrm{COOH}$ and $\mathrm{COO}^{-}$groups of glutamic (Glu) and aspartic (Asp) acid residues and aromatic amino acid residues. Moreover, it provides information about specific order of secondary structural changes and changes in side chains under various environments.

The first example of the application of 2D IR correlation spectroscopy to protein research was concerned with the secondary structure of myoglobin. In this study hydrogen-deuterium (H/D) exchange of the amide proteins was employed as an external perturbation to generate the $2 \mathrm{D}$ spectra [26]. Since that time 2D IR correlation spectroscopy has extensively been used to explore the secondary structure of proteins. Sefara and Richardson [27,28] studied thermal transitions in $\beta$-lactoglobulin (BLG) using both 2D IR and near-infrared (NIR) spectroscopy. Smeller and Heremans [29,30] and Dzwolak et al. [31] reported 2D IR studies of pressure-dependent structural modifications of proteins. Paquet et al. [32] employed 2D IR spectroscopy to investigate the aggregation of cytochrome $c$ in the presence of dimyristoylphophatidylglycerol. There are many other examples [33-40]. Czarnik-Matusewicz et al. [33] explored adsorption-induced and concentration-dependent structural variations of BLG in aqueous solutions by use of 2D attenuated total reflection (ATR)/IR correlation spectroscopy.

Very recently, new types of applications of 2D IR correlation spectroscopy to protein research have been presented. Murayama et al. [34] extended 2D IR correlation spectroscopy studies of proteins to those of hydrogen bondings of side chains of human serum albumin (HSA) in aqueous solutions. Wu et al. [35] combined principal component analysis with 2D correlation spectroscopy to investigate the secondary structure and kinetics of H/D exchange of HSA.

\section{Principles of 2D correlation spectroscopy}

Figure 1 shows a general scheme for obtaining 2D correlation spectra [18]. When an arbitrary perturbation is applied to a system, various chemical constituents of the system are selectively excited. The excitation and subsequent relaxation process toward the equilibrium can be monitored with electromagnetic probes. The intensity changes, band shifs, and changes in band shapes are typical spectral variations observed under external perturbation. The monitored fluctuations of spectral signals are then transformed into 2D spectra by use of a correlation method. However, before the calculation of 2D correlation spectra, dynamic spectra must first be calculated. 


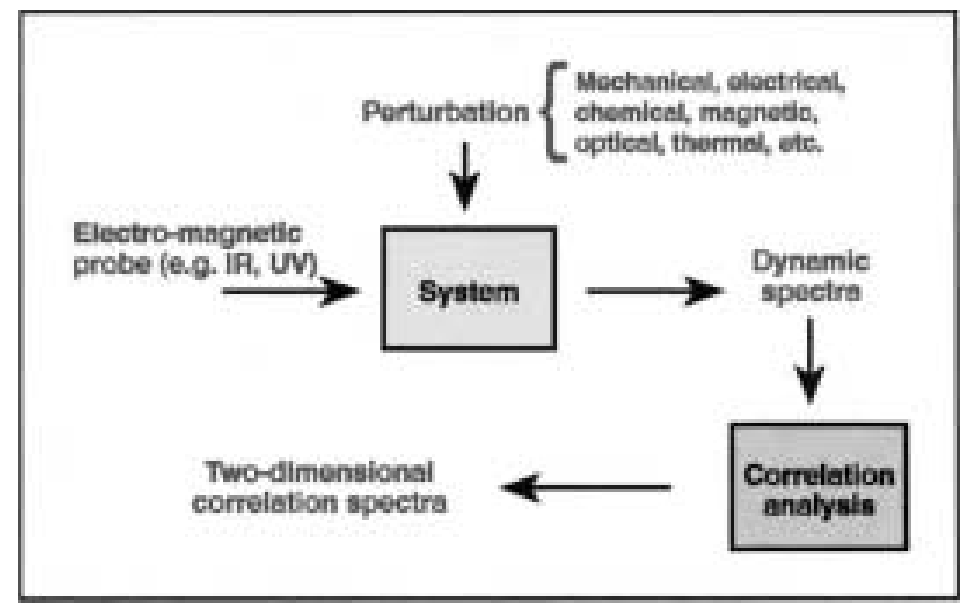

Fig. 1. General scheme for obtaining 2D correlation spectra. (Reproduced from [18] with permission. (C)2000, Society for Applied Spectroscopy.)

\subsection{Dynamic spectra}

For a spectral intensity variation $y(\nu, t)$ observed as a function of a spectral variable $\nu$ during an interval of some additional external variable $t$ between $T_{\min }$ and $T_{\max }$, the dynamic spectrum $\tilde{y}(\nu, t)$ is defined as

$$
\tilde{y}(\nu, t)= \begin{cases}y(\nu, t)-\bar{y}(\nu) & \text { for } T_{\min } \leqslant t \leqslant T_{\max } \\ 0 & \text { otherwise. }\end{cases}
$$

The external variable $t$ will be referred to as time for convenience, although it can be any reasonable measure of a physical quantity, such as temperature, pressure, and concentration. The reference spectrum $\bar{y}(\nu)$ may often be set to the time-averaged spectrum defined by

$$
\bar{y}(\nu)=\frac{1}{T_{\max }-T_{\min }} \int_{T_{\min }}^{T_{\max }} y(\nu, t) \mathrm{d} t
$$

although other forms of reference spectra may also be chosen.

\subsection{Generalized $2 D$ correlation spectra}

A formal definition of the generalized 2D correlation spectrum is given by [17]

$$
\Phi\left(\nu_{1}, \nu_{2}\right)+\mathrm{i} \Psi\left(\nu_{1}, \nu_{2}\right)=\frac{1}{\pi\left(T_{\max }-T_{\min }\right)} \int_{0}^{\infty} \tilde{Y}_{1}(\omega) \cdot \tilde{Y}_{2}^{*}(\omega) \mathrm{d} \omega
$$

The synchronous and asynchronous 2D correlation spectra, $\Phi\left(\nu_{1}, \nu_{2}\right)$ and $\Psi\left(\nu_{1}, \nu_{2}\right)$, represent, respectively, the overall similarities and differences of the time-dependent behavior of spectral intensity variations measured at two distinct spectral variables, $\nu_{1}$ and $\nu_{2}$, during the observation period between $T_{\min }$ and $T_{\max }$. The term $\tilde{Y}_{1}(\omega)$ is the forward Fourier transform of the spectral intensity variations $\tilde{y}\left(\nu_{1}, t\right)$ 
observed at some spectral variable $\nu_{1}$

$$
\begin{aligned}
\tilde{Y}_{1}(\omega) & =\int_{-\infty}^{\infty} \tilde{y}\left(\nu_{1}, t\right) \mathrm{e}^{-\mathrm{i} \omega t} \mathrm{~d} t, \\
& =\tilde{Y}_{1}^{\operatorname{Re}}(\omega)+\mathrm{i} \tilde{Y}_{1}^{\operatorname{Im}}(\omega),
\end{aligned}
$$

where $\tilde{Y}_{1}^{\operatorname{Re}}(\omega)$ and $\tilde{Y}_{1}^{\operatorname{Im}}(\omega)$ are, respectively, the real and the imaginary components of the Fourier transform. The Fourier frequency $\omega$ represents the individual frequency component of the variation of $\tilde{y}\left(\nu_{1}, t\right)$ measured along the variable $t$. Likewise, the conjugate of the Fourier transform $\tilde{Y}_{2}^{*}(\omega)$ of spectral intensity variations $\tilde{y}\left(\nu_{2}, t\right)$ observed at spectral variable $\nu_{2}$ is given by

$$
\begin{aligned}
\tilde{Y}_{2}^{*}(\omega) & =\int_{-\infty}^{\infty} \tilde{y}\left(\nu_{2}, t\right) \mathrm{e}^{+\mathrm{i} \omega t} \mathrm{~d} t, \\
& =\tilde{Y}_{2}^{\operatorname{Re}}(\omega)-\mathrm{i} \tilde{Y}_{2}^{\operatorname{Im}}(\omega) .
\end{aligned}
$$

\subsection{Synchronous and asynchronous spectra}

Examples of the synchronous and asynchronous 2D correlation spectra are shown in Fig. 2(A) and (B), respectively [18]. A synchronous spectrum is symmetric with respect to a diagonal line corresponding to spectral coordinates, $\nu_{1}=\nu_{2}$. The intensities of peaks on the diagonal line correspond to the autocorrelation function of spectral intensity variations observed during a period $T$. Those peaks are therefore referred to as autopeaks. The intensities of autopeaks represent the overall extent of dynamic fluctuations of spectral signals. Cross peaks located at the off-diagonal positions of a synchronous spectrum represent the simultaneous changes of spectral signals at two different wavenumbers. If the sign of a cross peak is positive, it means that spectral intensities at corresponding wavenumbers are either increasing or

( A )

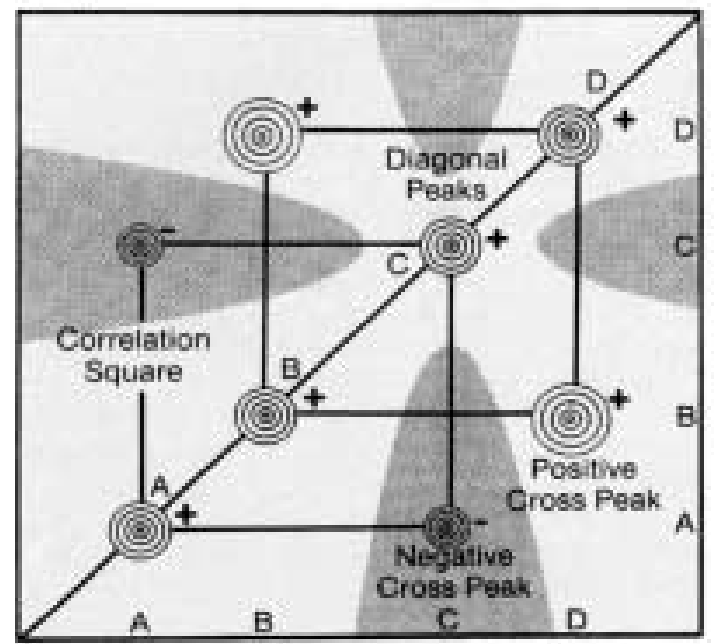

Wavenumber, $v_{1}$
( B )

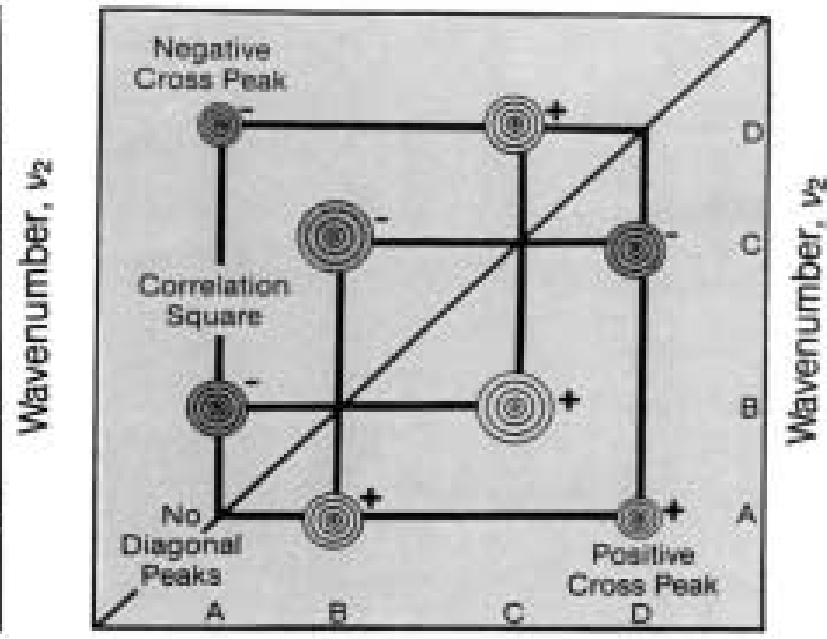

Wavenumber, $v_{1}$

Fig. 2. (A) Schematic contour map of a synchronous 2D correlation spectrum. (B) Schematic contour map of an asynchronous 2D correlation spectrum. (Reproduced from [18] with permission. (C)2000, Society for Applied Spectroscopy.) 
decreasing together. If the sign is negative, it is indicated that one spectral intensity is increasing while the other is decreasing.

An asynchronous 2D correlation spectrum, which consists exclusively of off-diagonal cross peaks, provides information complementary to the synchronous spectrum. Asynchronous cross peaks develop only if the basic trends of dynamic spectral variations observed at two different wavenumbers of the cross peaks are dissimilar. The sign of an asynchronous cross peak can be either positive or negative. If the intensity change at $\nu_{1}$ takes place predominantly before that at $\nu_{2}$, the sign is positive. On the other hand, if the change at $\nu_{1}$, occurs after that at $\nu_{2}$, the sign becomes negative. It must be kept in mind that this rule is reversed if $\Phi\left(\nu_{1}, \nu_{2}\right)<0$.

\section{Application of 2D IR correlation spectroscopy to protein research}

In this section we introduce three examples of 2D IR studies on proteins from our recent research [3335].

\subsection{D ATR/IR correlation spectroscopy study of concentration-dependent structural variations of $\beta$-lactoglobulin in aqueous solutions}

Czarnik-Matusewicz et al. [33] studied adsorption-induced and concentration-dependent structural modifications of $\beta$-lactoglobulin (BLG) in aqueous solutions by use of 2D ATR/IR correlation spectroscopy. A number of studies have been reported for the secondary structural changes of BLG under various perturbations such as temperature, $\mathrm{pH}$, pressure, concentration and dielectric constant of solvent [41-43]. It is of particular interest that even the concentration changes induce secondary structural modifications in BLG [43].

Figure 3 depicts ATR/IR spectra in the $4000-650 \mathrm{~cm}^{-1}$ region of BLG solutions with a concentration of $1,2,3,4$, and $5 \mathrm{wt} \%$ and a phosphate buffer solution $(\mathrm{pH} 6.6)$ [33]. The spectra are very close to

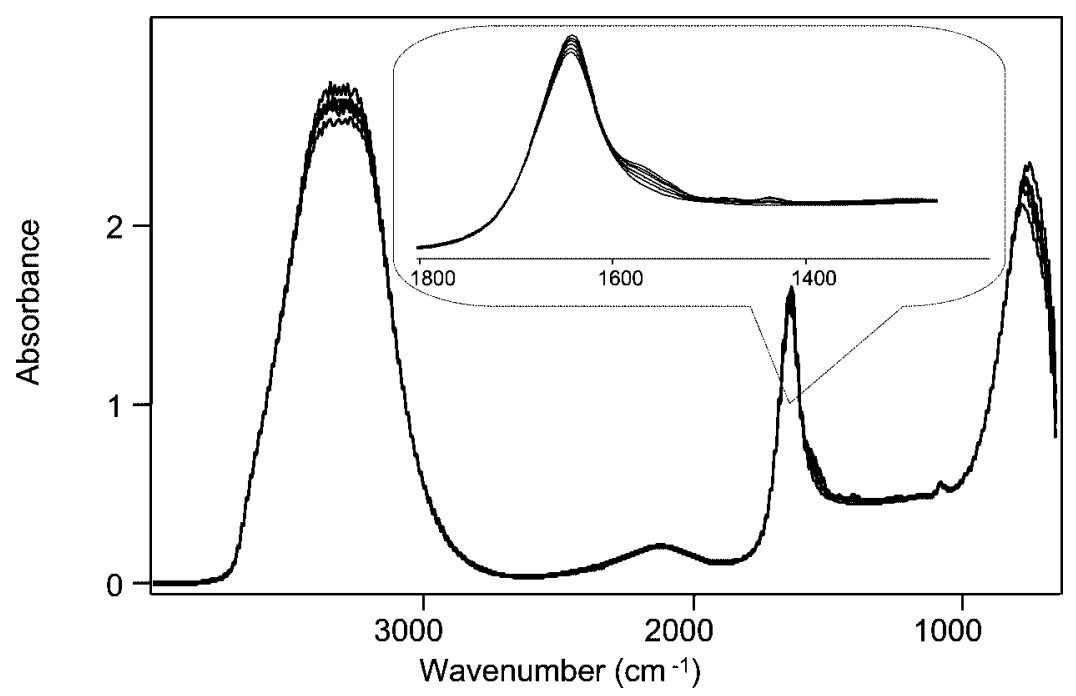

Fig. 3. ATR/IR spectra in the $4000-650 \mathrm{~cm}^{-1}$ region of the buffer solution and five different aqueous solutions of BLG with concentrations of $1,2,3,4$, and $5 \mathrm{wt} \%$. (Reproduced from [33] with permission. (c) 2000, American Chemical Society.) 


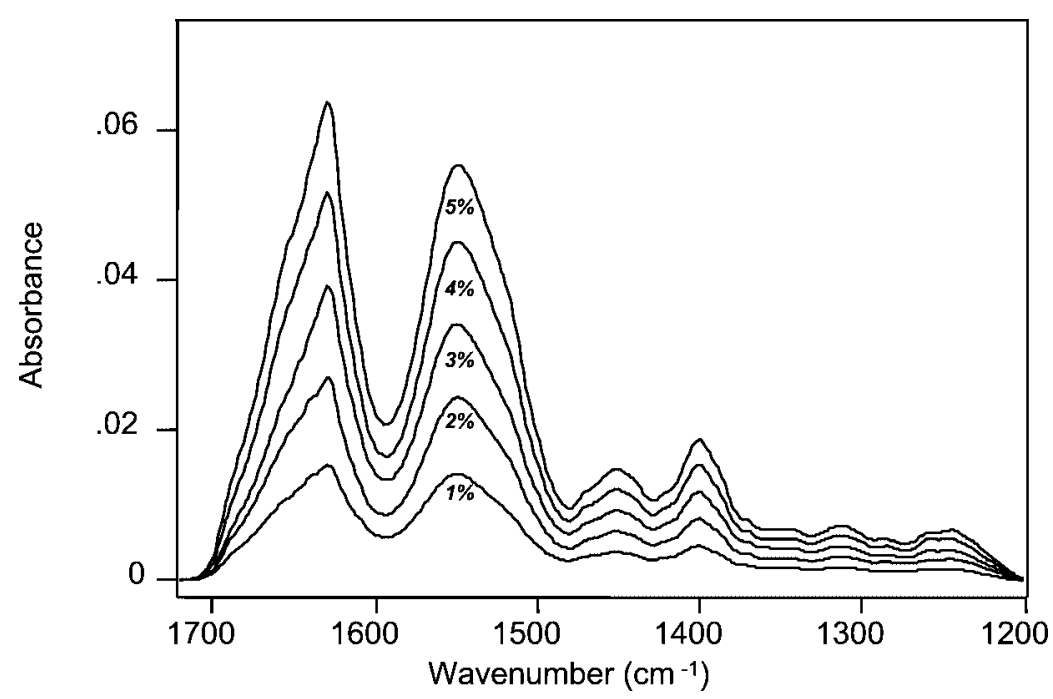

Fig. 4. Concentration-dependent ATR/IR spectral variations in the $1720-1200 \mathrm{~cm}^{-1}$ region of the BLG solutions after the four pretreatments, except for normalization. (Reproduced from [33] with permission. (C)2000, American Chemical Society.)

an ATR/IR spectrum of water. To extract concentration-dependent spectral changes, the original spectra were subjected to pretreatment procedures consisting of ATR correction, subtraction of the spectrum of the buffer solution, smoothing, and normalization over the concentration [33]. Figure 4 shows the resulting spectra of the protein solutions after the four pretreatments expect for the normalization [33]. Czarnik-Matusewicz et al. [33] examined both adsorption-induced and concentration-dependent spectral variations of BLG using 2D ATR/IR correlation spectroscopy. It was found from the adsorptiondependent spectral changes that the interaction between BLG molecules and an ATR prism is characterized by intensity changes in bands assigned to $\beta$-sheet elements buried in the hydrophobic core of the molecule and that the intensity variations induced by the adsorption are about one-tenth of those induced by the concentration changes [33]. In this review only the concentration-dependent structural changes in BLG are discussed.

Figure 5 illustrates the synchronous 2D ATR/IR correlation spectrum calculated from the concentrationdependent spectral changes of the BLG aqueous solutions. The strongest autopeaks at 1652 and $1662 \mathrm{~cm}^{-1}$ are assigned to hydrophilic secondary structure motives located on the outer surface of BLG that are built from $\alpha$-helices and $3_{10}$-helices, respectively. These secondary structures are less protected from water penetration than the $\beta$-strands forming the calyx. A minimal intensity variation in the band at $1636 \mathrm{~cm}^{-1}$ due to antiparallel "buried" $\beta$-sheets is consistent with the fact that the $\mathrm{C}=\mathrm{O}$ groups located inside the hydrophobic core of BLG are more resistant to the interaction with water molecules than those in the hydrophilic, solvent exposed part of BLG.

Figure 6 depicts the corresponding asynchronous correlation spectrum and Fig. 7 shows a slice spectrum extracted at $1665 \mathrm{~cm}^{-1}$ from the asynchronous 2D spectrum in Fig. 6, together with that at $1640 \mathrm{~cm}^{-1}$ from the asynchronous spectrum calculated from the adsorption-dependent spectral changes [33]. It can be seen from comparison between the two slice spectra that the unrelated intensity variations stimulated by concentration change are at least one order of magnitude higher than those induced by the adsorption process. According to the rule proposed by Noda $[17,18]$, the asynchronous spectrum in Fig. 6 and the slice spectrum at $1665 \mathrm{~cm}^{-1}$ in Fig. 7 suggest the following sequence of the 


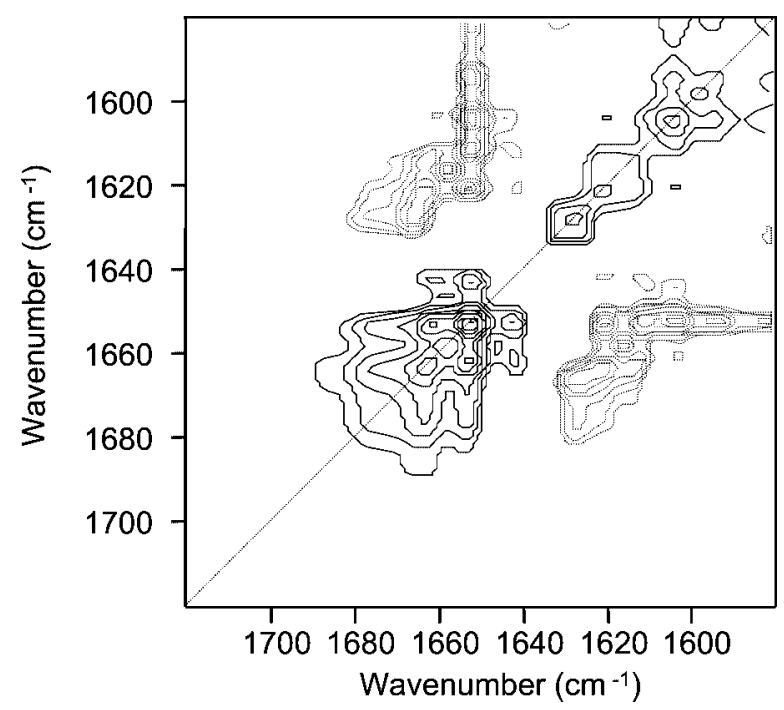

Fig. 5. Synchronous 2D ATR/IR correlation spectrum in the $1720-1580 \mathrm{~cm}^{-1}$ region constructed from concentration-dependent spectral changes of BLG. (Reproduced from [33] with permission. (C)2000, American Chemical Society.)

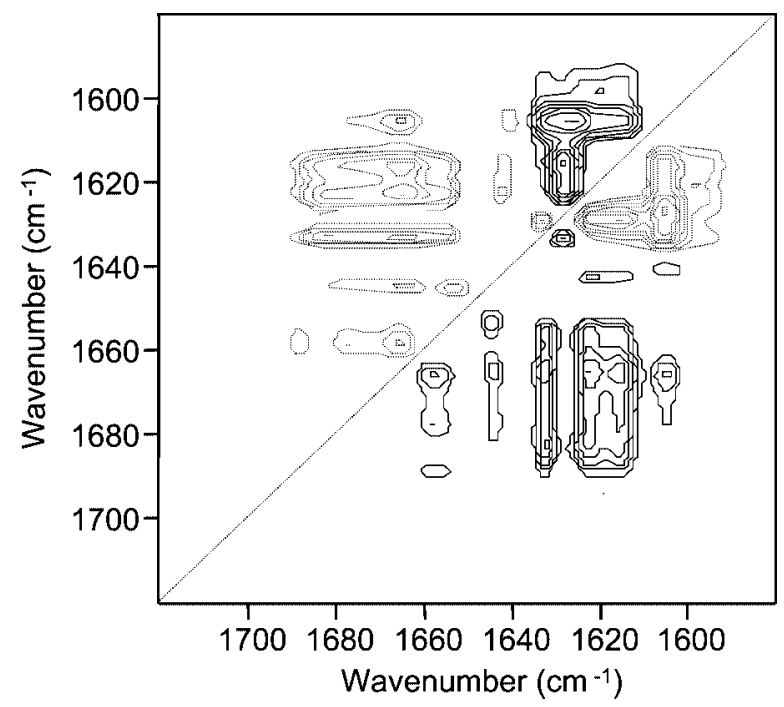

Fig. 6. Asynchronous 2D ATR/IR correlation spectrum in the $1720-1580 \mathrm{~cm}^{-1}$ region constructed from concentration-dependent spectral changes of BLG. (Reproduced from [33] with permission. (C)2000, American Chemical Society.)

spectral events occurring during the concentration increase:

$$
\begin{aligned}
& (1645 \approx 1642) \rightarrow(1694 \approx 1683 \approx 1658 \approx 1654) \rightarrow 1673 \approx 1665 \rightarrow(1638 \approx 1633 \approx 1628) \rightarrow \\
& 1623 \rightarrow 1616 \rightarrow 1606 \mathrm{~cm}^{-1} .
\end{aligned}
$$

The above sequence reveals that the first event in the intensity variations occur for the bands due to the random coil structure $\left(1645\right.$ and $\left.1642 \mathrm{~cm}^{-1}\right)$, followed by the intensity changes in the bands assigned to the high-wavenumber $\beta$-sheet component $\left(1694 \mathrm{~cm}^{-1}\right), \beta$-turn $\left(1683 \mathrm{~cm}^{-1}\right)$, and $\alpha$-helix 


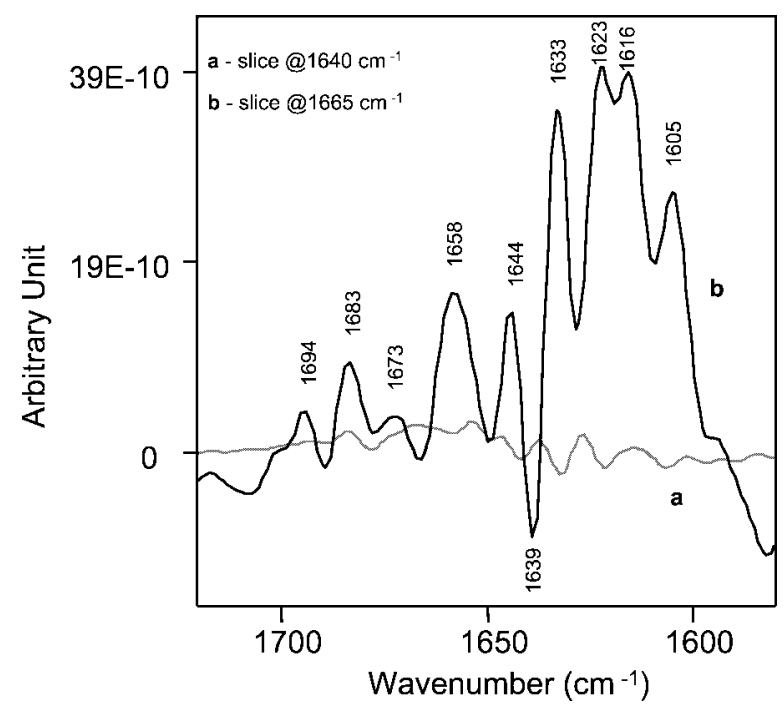

Fig. 7. Slice spectra extracted along (a) $1640 \mathrm{~cm}^{-1}$ in the asynchronous spectrum generated from the adsorption-dependent spectral variations and (b) $1665 \mathrm{~cm}^{-1}$ in the asynchronous spectrum presented in Fig. 6. (Reproduced from [33] with permission. (c)2000, American Chemical Society.)

(1658 and $1654 \mathrm{~cm}^{-1}$ ). The intensity variations arising from another type of $\beta$-turn (probably type III) $\left(1673 \mathrm{~cm}^{-1}\right)$ and 310 helix $\left(1665 \mathrm{~cm}^{-1}\right)$ take place next. The intensity modifications attributed to both buried $\left(1638 \mathrm{~cm}^{-1}\right)$ and exposed $\beta$-strands $\left(1633\right.$ and $\left.1628 \mathrm{~cm}^{-1}\right)$ are behind those due to the structures described above, but ahead the changes induced by aggregated components $\left(1623 \mathrm{~cm}^{-1}\right)$. The last event in the sequence is attributed to the side-chain vibrations $\left(1616\right.$ and $\left.1606 \mathrm{~cm}^{-1}\right)$. The negative sign of the synchronous peak around $(1652,1622) \mathrm{cm}^{-1}$ suggests that, at the expense of the intramolecular hydrogen bonds located in the disordered/ $\alpha$-helix components, the number of intermolecular hydrogen bonds increases. This conclusion is consistent with those reached from thermal denaturation studies of BLG by IR spectroscopy [41] and circular dichroism [42].

\section{2. $2 D$ ATR/IR correlation spectroscopy study on $p H$-dependent changes in the secondary structures and in the hydrogen bondings of side chains of human serum albumin}

Murayama et al. [34] applied 2D correlation spectroscopy to $\mathrm{pH}$-dependent ATR/IR spectral changes to explore $\mathrm{pH}$-dependent variations in the secondary structures and in the hydrogen bondings of side chains of HSA. HSA consists of three homologous domains I, II, and III built from 585 amino acid residues with a molecular weight of approximately $66.4 \mathrm{kDa}$ [44-46].

Figure 8 depicts a ribbon diagram of the structure of HSA drawn from the X-ray data by Carter and Ho. [47] HSA is composed of $67 \%$ helix, $10 \%$ turn, and $23 \%$ extended chain. No $\beta$-sheet structure is involved in HSA. It is well known that the three domains have different stability against external perturbation and that the $\alpha$-helix structures in HSA are considerably stable with temperature and $\mathrm{pH}$ changes. HSA undergoes several transitions in dependence of $\mathrm{pH}$, assuming $\mathrm{E}$ form (below $\mathrm{pH} 2.7$ ), F form ( $\mathrm{pH}$ 2.7-4.3), $\mathrm{N}$ form ( $\mathrm{pH} 4.3-8$ ), $\mathrm{B}$ form ( $\mathrm{pH} 8-10$ ), and $\mathrm{A}$ form (over $\mathrm{pH} 10$ ).

The 2D IR study provided unambiguous evidences for $\mathrm{pH}$-dependent changes in the secondary structures and hydrogen bondings of side chains, particularly of $\mathrm{COOH}$ and $\mathrm{COO}^{-}$groups of Glu and Asp and the relation between the changes in the secondary structures and the hydrogen bondings [34]. 


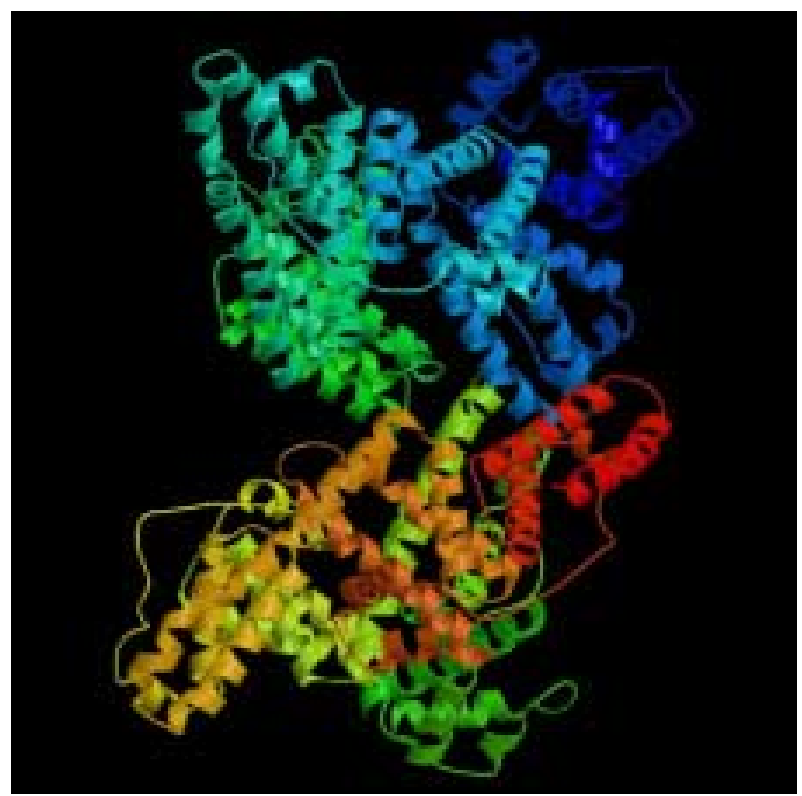

Fig. 8. Ribbon diagram of the structure of HSA drawn from the X-ray data by Carter and Ho. [47]

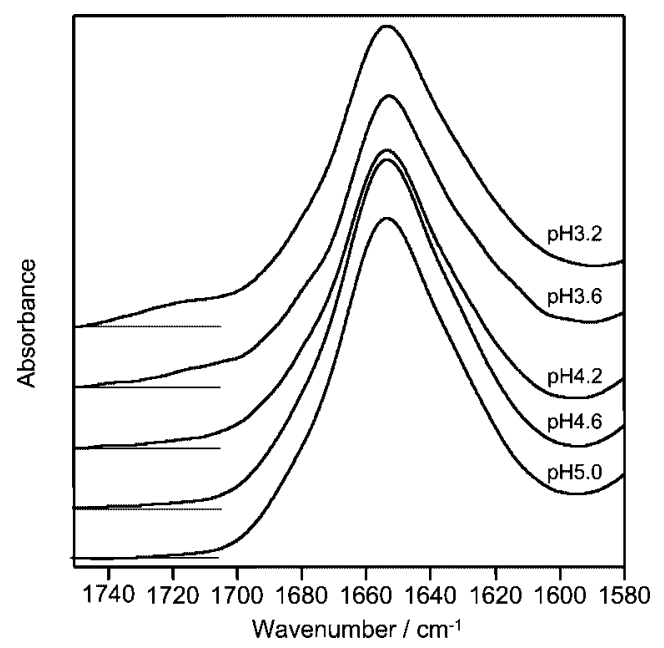

Fig. 9. Representative difference IR spectra in the $1750-1580 \mathrm{~cm}^{-1}$ region of HSA in buffer solutions (2.0 wt $\%$ ) of pH 3.2, 3.6, 4.2, 4.6 and 5.0. At each $\mathrm{pH}$ the spectrum of the buffer solution was subtracted from the corresponding spectrum of the HSA solution. (Reproduced from [34] with permission. (c)2001, American Chemical Society.)

\subsection{ATR/IR spectra of HSA in aqueous solutions}

Figures 9 and 10 show representative ATR/IR spectra in the $1750-1580 \mathrm{~cm}^{-1}$ region of HSA in aqueous solutions $(2.0 \mathrm{wt} \%)$ with $\mathrm{pH}$ of 3.2, 3.6, 4.2, 4.6, and 5.0, and their second derivatives, respectively [34]. The second derivative spectra reveal that the amide I band is composed of a strong band at $1654 \mathrm{~cm}^{-1}$ due to $\alpha$-helix and weak satellite components at 1681 and $1628 \mathrm{~cm}^{-1}$ assigned to the $\beta$-turn and $\beta$-strand structures, respectively. 


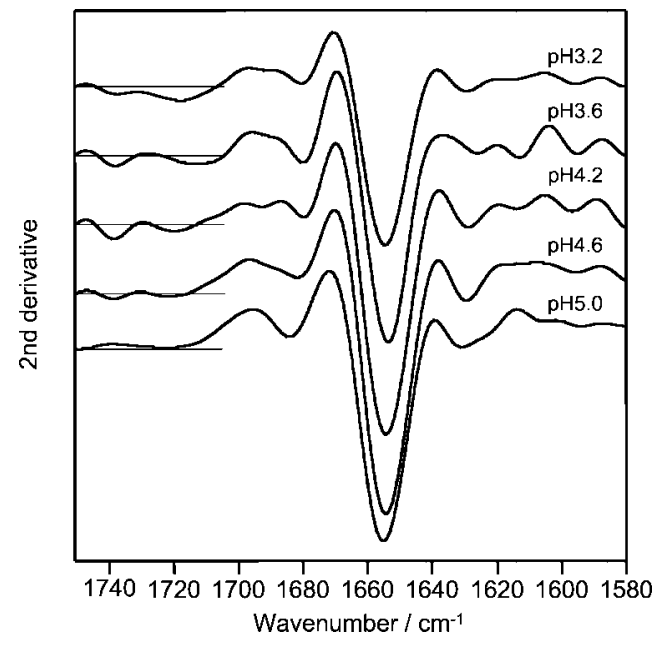

Fig. 10. Second derivaties of the spectra shown in Fig. 9. (Reproduced from [34] with permission. (c)2001, American Chemical Society.)

Table 1

Frequencies $\left(\mathrm{cm}^{-1}\right)$ and assignments of IR bands of the HSA solutions observed in the second derivative spectra and 2D correlation maps

\begin{tabular}{|c|c|c|c|c|}
\hline 2nd derivative & $\mathrm{N}$ form (2D) & $\mathrm{N}-\mathrm{F}$ transition $(2 \mathrm{D})$ & $\mathrm{F}$ form $(2 \mathrm{D})$ & Assignment \\
\hline 1740 & & 1740 & & Free $\mathrm{COOH}$ group \\
\hline \multirow[t]{3}{*}{1715} & 1715 & & 1715 & Hydrogen bonded (weak) $\mathrm{COOH}$ \\
\hline & & 1705 & & Hydrogen bonded (medium) $\mathrm{COOH}$ \\
\hline & & 1696 & 1696 & Hydrogen bonded (strong) $\mathrm{COOH}$ \\
\hline \multirow[t]{2}{*}{1681} & & & 1678 & $\beta$-turn \\
\hline & 1667 & & 1667 & $\beta$-turn \\
\hline \multirow[t]{4}{*}{1654} & 1654 & 1654 & & $\alpha$-helix \\
\hline & & & 1647 & Random coil \\
\hline & 1640 & 1640 & 1638 & $\beta$-strand \\
\hline & & 1632 & 1635 & $\beta$-strand \\
\hline \multirow[t]{2}{*}{1628} & & & & $\beta$-strand \\
\hline & & 1620 & 1622 & $\beta$-sheet \\
\hline 1614 & 1614 & & 1616 & Side chains \\
\hline 1598 & 1598 & & & $\mathrm{COO}^{-}$ \\
\hline
\end{tabular}

Of note in the second derivative spectra is appearance of weak features at 1740 and $1598 \mathrm{~cm}^{-1}$. They are ascribed to a $\mathrm{C}=\mathrm{O}$ stretching mode of $\mathrm{COOH}$ groups and $\mathrm{COO}^{-}$antisymmetric stretching mode, respectively, of Glu and Asp acid residues in HSA.

The wavenumbers of the bands observed in the second derivative spectra and their assignments are summarized in Table 1.

\section{4. $2 D$ correlation spectra of $N$ isomeric form of HSA}

Figure 11(A) and (B) show synchronous and asynchronous 2D IR correlation spectra of the $\mathrm{N}$ isomeric form of HSA in a buffer solution, constructual from the pH-dependent ( $\mathrm{pH}$ 5.0, 4.8, 4.6, and 4.4) spectral 

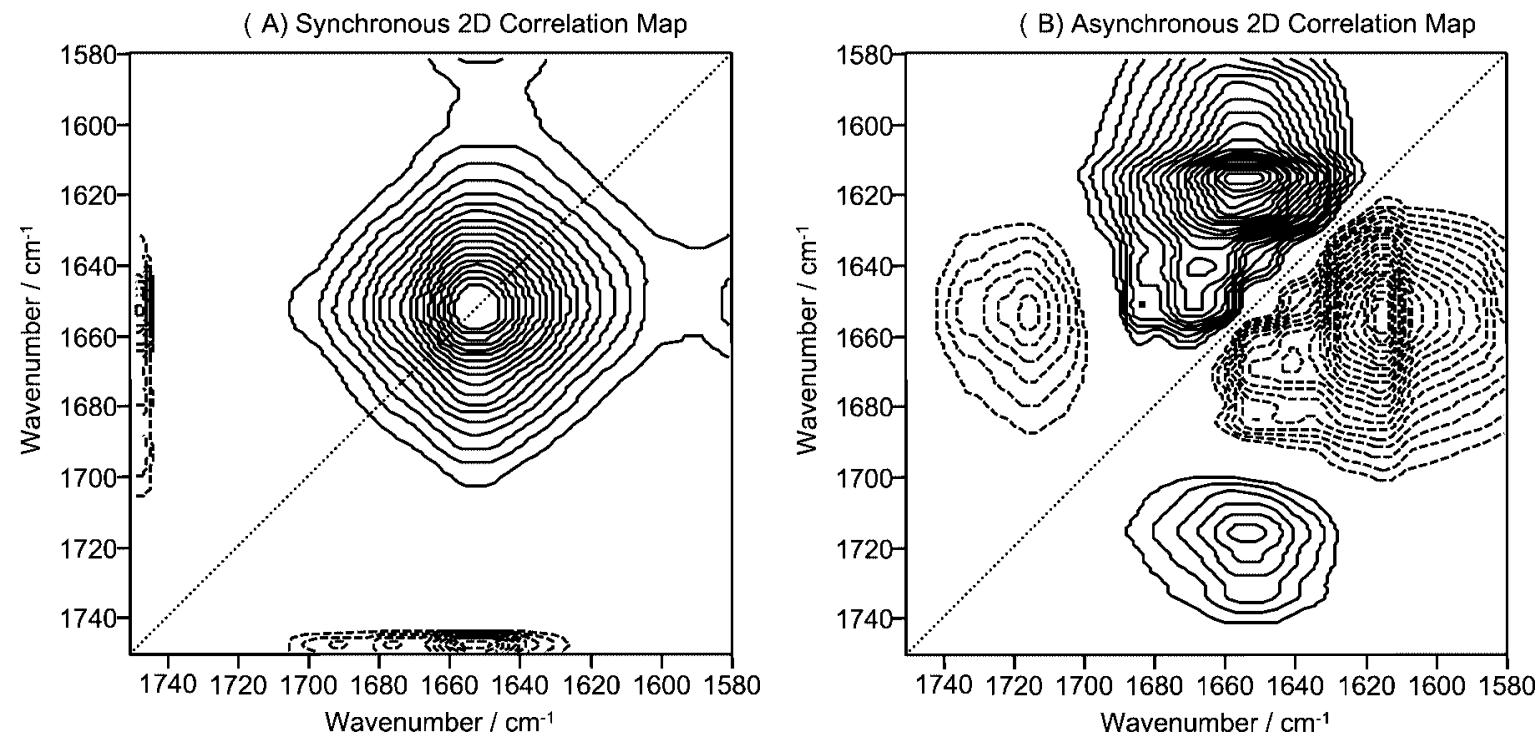

Fig. 11. (A) Synchronous 2D IR correlation spectrum in the $1750-1580 \mathrm{~cm}^{-1}$ region constructed from the pH-dependent ( $\mathrm{pH} 5.0,4.8,4.6$ and 4.4) spectral variations of the HSA solutions with a concentration of $2.0 \mathrm{wt} \%$. (B) The corresponding asynchronous correlation spectrum. (Reproduced from [34] with permission. (c)2001, American Chemical Society.)

variations in the $1750-1580 \mathrm{~cm}^{-1}$ region, respectively. A broad autopeak near $1654 \mathrm{~cm}^{-1}$ in the synchronous spectrum corresponds to the amide I band of the $\alpha$-helix structure of HSA. Several cross peaks are developed in the asynchronous spectrum, and from the analysis of the cross peaks, one can identify bands at least at $1715,1667,1654,1641$, and $1614 \mathrm{~cm}^{-1}$. The band at $1715 \mathrm{~cm}^{-1}$ is not identified in the second derivative spectra at $\mathrm{pH} 5.0$ and 4.6, demonstrating that 2D correlation spectroscopy is powerful in detecting subtle spectral changes. Murayama et al. [34] ascribed the band at $1715 \mathrm{~cm}^{-1}$ to a $\mathrm{C}=\mathrm{O}$ stretching mode of the hydrogen bonded $\mathrm{COOH}$ groups of Glu and Asp residues of HSA. About half of the carboxyls of Asp and Glu residues are considered to ionize with an intrinsic $\mathrm{p} K$ of 4.3. The asynchronous spectrum suggests that some carboxylate groups are protonated even in this $\mathrm{pH}$ range ( $\mathrm{pH}$ 4.0-5.0). The broad feature of the cross peak near $(1715,1654) \mathrm{cm}^{-1}$ indicates that the $\mathrm{COOH}$ groups with the hydrogen bonds of different strength are formed upon the protonation.

On the basis of the Noda's rule, Murayama et al. [34] deduced the following sequence of the intensity variations:

Hydrogen-bonded COOH $\left(1715 \mathrm{~cm}^{-1}\right)$, side chains $\left(1614 \mathrm{~cm}^{-1}\right) \rightarrow \alpha$-helix $\left(1654 \mathrm{~cm}^{-1}\right) \rightarrow$

$$
\beta \text {-strand }\left(1641 \mathrm{~cm}^{-1}\right) \rightarrow \beta \text {-turn }\left(1667 \mathrm{~cm}^{-1}\right) \text {. }
$$

\section{5. $2 D$ correlation spectra of $N-F$ transition region of $H S A$}

In the N-F transition the major structural changes take place in domain III and domain I undergoes only minor changes in the secondary structure [48]. Figure 12(A) and (B) illustrate the synchronous and asynchronous correlation spectra of the N-F transition, respectively. The synchronous spectrum yields a broad autopeak at $1654 \mathrm{~cm}^{-1}$ and negative cross peaks at $(1705,1632) \mathrm{cm}^{-1}$ and $(1740,1640) \mathrm{cm}^{-1}$. The bands at 1740 and $1705 \mathrm{~cm}^{-1}$ are due to a $\mathrm{C}=\mathrm{O}$ stretching vibration of free and hydrogen bonded $\mathrm{COOH}$ groups, respectively, of Asp and Glu side chains. In this $\mathrm{pH}$ range, many carboxylate groups are 

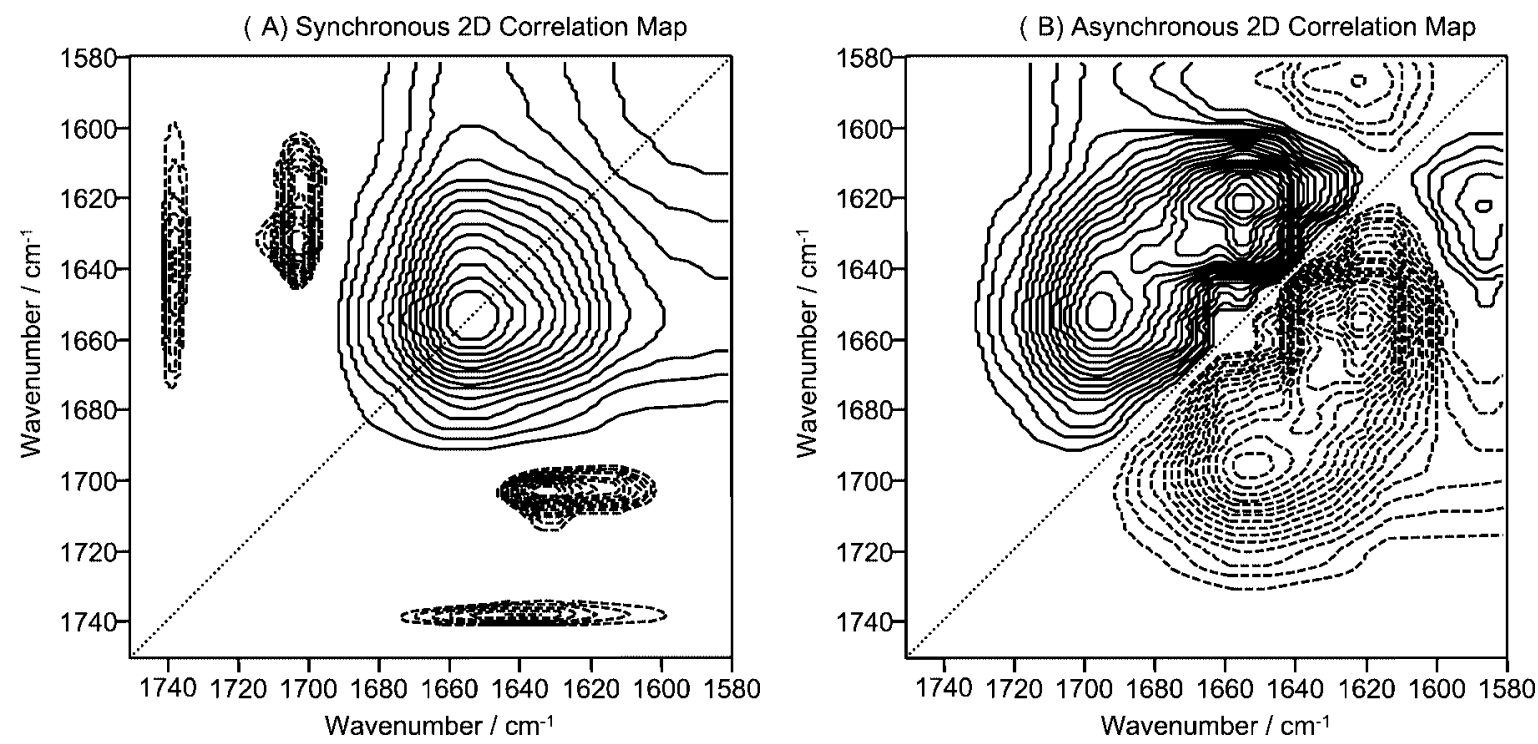

Fig. 12. (A) Synchronous 2D IR correlation spectrum in the $1750-1580 \mathrm{~cm}^{-1}$ region constructed from the pH-dependent (pH 4.6, 4.4, 4.2, 4.0 and 3.8) spectral variations of the HSA solutions with a concentration of $2.0 \mathrm{wt} \%$. (B) The corresponding asynchronous correlation spectrum. (Reproduced from [34] with permission. (C)2001, American Chemical Society.)

protonated. It is very likely that the unfolding or expansion of domain III induces the free $\mathrm{COOH}$ groups in the $\mathrm{N}-\mathrm{F}$ transition. The band at $1705 \mathrm{~cm}^{-1}$ due to the hydrogen bonded $\mathrm{COOH}$ group and that at $1632 \mathrm{~cm}^{-1}$ assignable to $\beta$-strand structures share the cross peak, suggesting that the formation of the hydrogen bonded $\mathrm{COOH}$ groups upon the protonation and the secondary structure change in $\beta$-strand structures are cooperative in the $\mathrm{N}-\mathrm{F}$ transition.

The asynchronous spectrum (Fig. 12(B)) develops cross peaks at $(1696,1654)$ and $(1620,1654) \mathrm{cm}^{-1}$. The bands at 1696, 1654, and $1620 \mathrm{~cm}^{-1}$ may be due to hydrogen bonded $\mathrm{COOH}$ groups, $\alpha$-helices, and $\beta$-sheets, respectively. Of note is that two kinds of hydrogen bonded $\mathrm{COOH}$ groups show the $\mathrm{C}=\mathrm{O}$ stretching mode at 1705 and $1696 \mathrm{~cm}^{-1}$ in the N-F transition. It seems that they hydrogen bonds of different strength. The $\mathrm{C}=\mathrm{O}$ groups can form hydrogen bonds with $\mathrm{NH}$ groups of the main chains or side chains or with $\mathrm{OH}$ groups of side chains or water molecules. This shows that $2 \mathrm{D}$ correlation spectroscopy enables one to investigate the $\mathrm{C}=\mathrm{O}$ stretching bands arising from $\mathrm{COOH}$ groups located in a variety of environments. The signs of the asynchronous cross peaks indicate the following sequence of the structural changes in HSA during the N-F transition.

$$
\begin{aligned}
& \text { Hydrogen bonded COOH }\left(1696 \mathrm{~cm}^{-1}\right) \rightarrow \alpha \text {-helix }\left(1654 \mathrm{~cm}^{-1}\right) \rightarrow \\
& \beta \text {-sheet }\left(1620 \mathrm{~cm}^{-1}\right), \beta \text {-turn }\left(1667 \mathrm{~cm}^{-1}\right) \rightarrow \beta \text {-strand }\left(1632 \mathrm{~cm}^{-1}\right) .
\end{aligned}
$$

The above sequence suggests that the protonation of $\mathrm{COO}^{-}$groups starts the $\mathrm{N}-\mathrm{F}$ transition, followed by the unfolding of the $\alpha$-helices in domain III. In the last step, the $\beta$-turns, $\beta$-sheets, and $\beta$-strands undergo the secondary structure change, leading to the F isomeric form of HSA. 


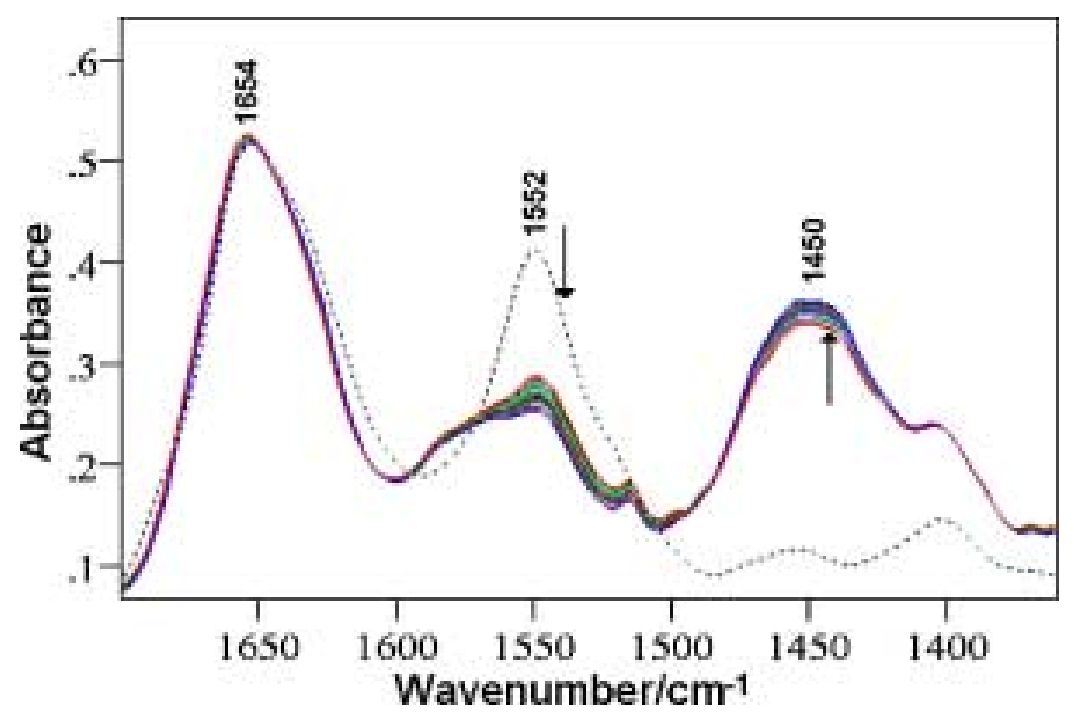

Fig. 13. An FT-IR spectrum of $\mathrm{HSA}$ in a $\mathrm{H}_{2} \mathrm{O}$ solution and those of $\mathrm{HSA}$ in a $\mathrm{D}_{2} \mathrm{O}$ solution as a function of exposure time. The spectrum with the dotted line; the $\mathrm{H}_{2} \mathrm{O}$ solution: The spectra with solid line; the $\mathrm{D}_{2} \mathrm{O}$ solution measured (from top to bottom) from 1.5 to $260 \mathrm{~min}$ after the initiation of the exposure of $\mathrm{HSA}$ to $\mathrm{D}_{2} \mathrm{O}$ at $25^{\circ} \mathrm{C}$. In each spectrum the spectrum of $\mathrm{H}_{2} \mathrm{O}$ or $\mathrm{D}_{2} \mathrm{O}$ was subtracted. (Reproduced from [35] with permission. (C)2001, American Chemical Society.)

\section{6. $2 D$ IR spectroscopy and principal component analysis studies of the secondary structure of human serum albumin in aqueous solutions using hydrogen-deuterium exchange}

IR spectra were measured as a function of time after dissolving $\mathrm{HSA}$ into $\mathrm{D}_{2} \mathrm{O}$ to investigate the secondary structure and kinetics of H/D exchange [35]. 2D IR correlation spectroscopy and PCA were used to analyze the obtained spectra [35]. 2D IR spectra in the amide I and amide II (and amide II') regions were generated from time-dependent spectral variations in different exposure time domains of $\mathrm{HSA}$ in the $\mathrm{D}_{2} \mathrm{O}$ solution. The synchronous and asynchronous spectra in each time domain provided a clear separation of amide bands due to the different secondary structures and the asynchronous spectra showed the specific sequence of the secondary structure exposed to the H/D exchange. PCA was used to select the appropriate time domains for the calculation of 2D correlation spectra. The loadings plots of PCA are useful also to assist the band assignments in the amide I and II region and to investigate the mechanism of the H/D exchange.

\subsection{Hydrogen-deuterium exchanges in amide protons of HSA monitored by IR spectra}

Figure 13 shows a series of IR spectra measured as a function of time after dissolving HSA into $\mathrm{D}_{2} \mathrm{O}$ $\left(\mathrm{pD} 7.0, \mathrm{pD}=\mathrm{pD}_{\text {read }}+0.44\right)[35]$. The spectrum shown by a broken line is the spectrum of HSA in $\mathrm{H}_{2} \mathrm{O}$. The amide I region shows a broad maximum at $1654 \mathrm{~cm}^{-1}$ characteristic of a $\alpha$-helical structure. Of note in Fig. 13 is a dramatic decrease in the intensity of the amide II band centered at $1552 \mathrm{~cm}^{-1}$ and a concomitant intensity increase at $1450 \mathrm{~cm}^{-1}$ (amide $\mathrm{II}^{\prime}$ ). The intensity decrease in the amide II band provides a direct measure for both the time course and the extent of amide H/D exchange (see Fig. 14).

Wu et al. [35] monitored the reaction of $-\mathrm{CONH}-+\mathrm{D}_{2} \mathrm{O} \rightarrow-\mathrm{COND}-+$ HOD by measuring the decrease in the intensity of the amide II region. One can assume that during the H/D exchange the intensity of the amide I band in the $1700-1600 \mathrm{~cm}^{-1}$ region remains constant. Therefore, Wu et al. [35] took the 

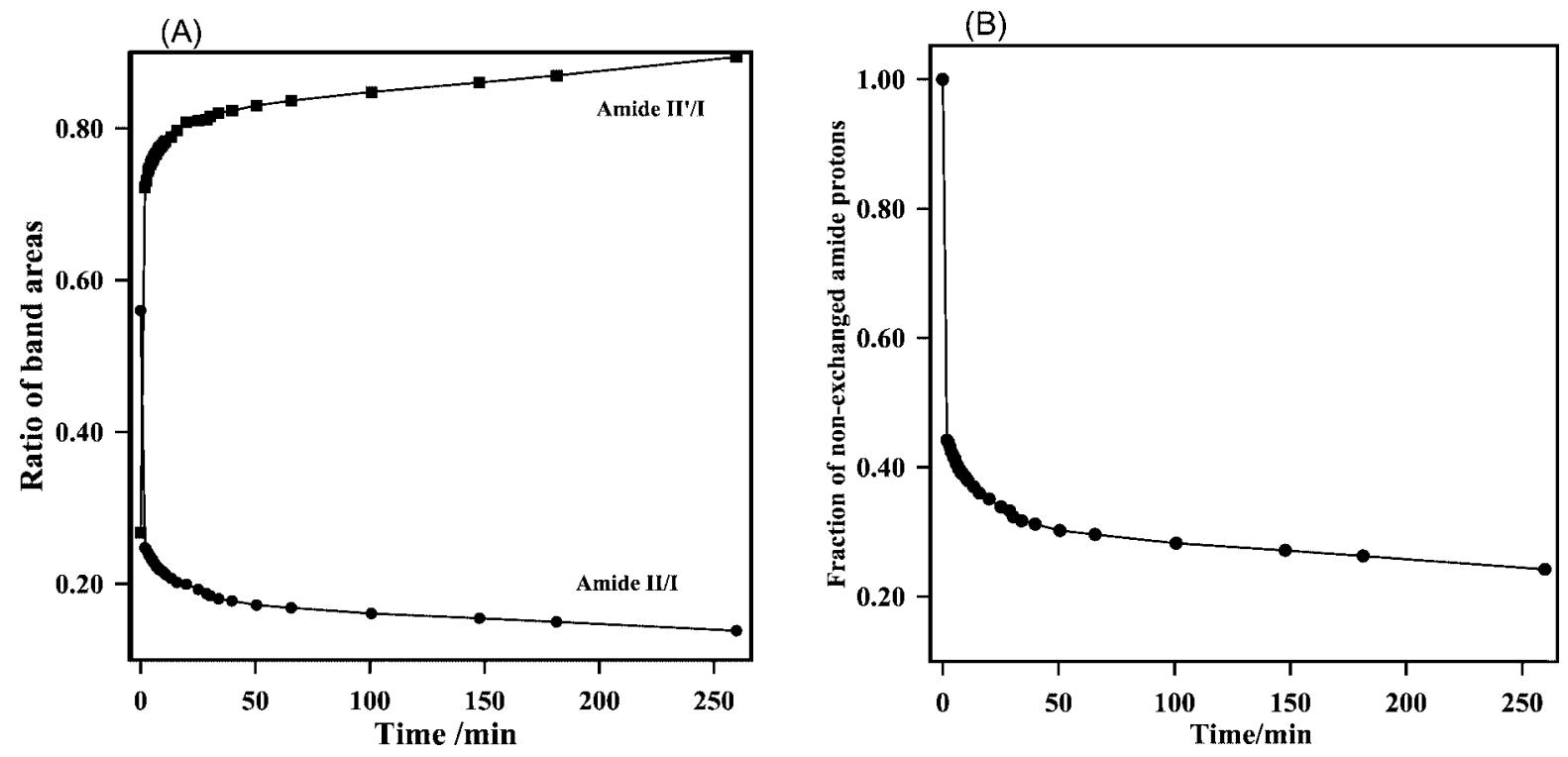

Fig. 14. (A) The ratios of the area of amide II or amide II' divided by that of amide I for the spectra shown in Fig. 13 versus time after the initiation of the H/D exchange in HSA in the $\mathrm{D}_{2} \mathrm{O}$ solution. (B) Fraction of the non-exchanged amide protons in HSA in the $\mathrm{D}_{2} \mathrm{O}$ solution. (Reproduced from [35] with permission. (C)2001, American Chemical Society.)

ratio of the area of the amide II band (or amide $\mathrm{II}^{\prime}$ ) to that of the amide I band centred at $1654 \mathrm{~cm}^{-1}$ ( $A_{\text {amide II }} / A_{\text {amide I }}$ or $A_{\text {amide II }} / A_{\text {amide I }}$ ) to eliminate possible fluctuations in intensity. In order to estimate the fraction of the non-exchanged amide protons $(X)$, the initial value of $A_{\text {amide II }} / A_{\text {amide I }}$ is expressed by the ratio of the area of the amide II band to that of amide I band of HSA in the $\mathrm{H}_{2} \mathrm{O}$ solution [35]. It was found that the initial value of $A_{\text {amide II }} / A_{\text {amide I }}$ is 0.56 .

The ratios of $A_{\text {amide II }} / A_{\text {amide I }}$ and $A_{\text {amide II }} / A_{\text {amide I }}$ are plotted as a function of the time in Fig. 14(A). The decrease in the $A_{\text {amide II }} / A_{\text {amide I }}$ may be ascribed as the sum of the individual exponential decay for each amide proton. It is noted that a large number of amide protons remain unchanged even after a few hours. The fraction, $X$, of the non-exchanged amide protons at a time, $t$, can be estimated as:

$$
X=A_{\text {amide II }} / 0.56 A_{\text {amide } \mathrm{I}} \text {. }
$$

Figure 14(B) plots the fraction of $X$ versus time [35]. Figure 14(B) reveals that roughly 50\% of the amide protons undergo the H/D exchange within 2 min after the exposure of HSA to $\mathrm{D}_{2} \mathrm{O}$, additional $12 \%$ over the next $30 \mathrm{~min}$, and further $10 \%$ over the next a few hours. Roughly $25 \%$ of the amide protons resist to being deuterated even 4 hour after the exposure of $\mathrm{HSA}$ to $\mathrm{D}_{2} \mathrm{O}$ at $25^{\circ} \mathrm{C}$.

\subsection{PCA Study}

Figure 15 shows a PC1 vs PC2 score plot of the time-dependent IR spectra in the $1720-1360 \mathrm{~cm}^{-1}$ region [35]. The two PCs account for nearly $99.9 \%$ of the total variance. One can easily find three groups, Group I, II and III in the score plot. Group I, II, and III comprise the spectra measured between 1.8 (HD02) and 5.3 (HD06) min, between 6.4 (HD07) and 13.4 (HD16) min, and between 25.2 (HD19) and 181 (HD27) min after the initiation of the H/D exposure, respectively. The result in Fig. 15 provides very important basis for the selection of the time domains for the $2 \mathrm{D}$ correlation analysis. 


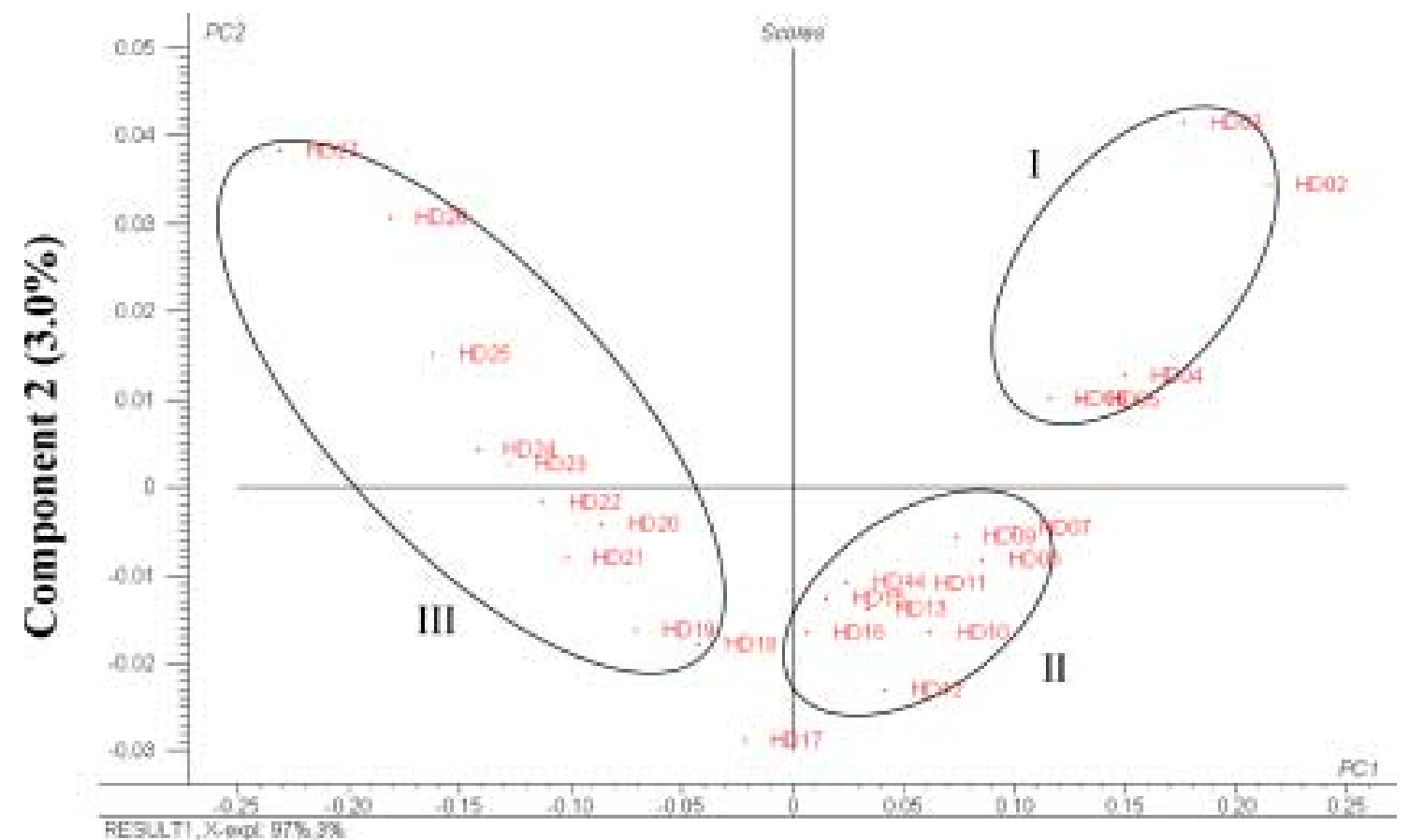

Component $1(97.0 \%)$

Fig. 15. A PC1 vs PC2 plot of PCA for the time-dependent IR spectra of HSA shown in Fig. 13. (Reproduced from [35] with permission. (c) 2001, American Chemical Society.)

The loadings plots of PC1 and PC2 for the score plot in Fig. 15 are shown in Fig. 16(A) and (B), respectively [35]. In the loadings plot of PC1 positive peaks are developed around 1682, 1667, 1663, and $1540 \mathrm{~cm}^{-1}$, which correspond to the bands due to $\beta$-turn (bands at 1682, 1667, and $1663 \mathrm{~cm}^{-1}$ in the amide I region) and $\beta$-strand (a band at $1540 \mathrm{~cm}^{-1}$ in the amide II region). This means that in Group I and Group II the H/D exchanges occur largely in the amide groups of $\beta$-turns. A negative peak at $1625 \mathrm{~cm}^{-1}$ and those at 1452 and $1437 \mathrm{~cm}^{-1}$ may be due to the amide I band of intermolecular $\beta$-strands and the amide II' $^{\prime}$ bands of $\alpha$-helices overlapped with the band arising from the bending mode of HOD, respectively. It seems that the formation of the intermolecular $\beta$-strands, HOD, and the deuterated $\alpha$-helices are predominant in Group III.

The loadings plot of PC2 shows all positive bands at 1698, 1687, 1672, 1666, 1650, 1630, and $1620 \mathrm{~cm}^{-1}$ in the amide I region, those at 1573,1558 and $1538 \mathrm{~cm}^{-1}$ in the amide II region, and those at 1468 and $1460 \mathrm{~cm}^{-1}$ in the amide II' region. These positive peaks mean that Group I and Group III are characterized by these band features. They contribute greatly to the separation of Group I and Group III from Group II, especially the separation between Group I and Group II. Even though the characteristic features of Group I and Group II are the H/D exchanges in the $\beta$-turns, there are still great differences between them as revealed by the positive peaks in the loadings plot for PC2. The loadings plot for PC2 suggest that in Group III the H/D exchanges take place largely in the $\alpha$-helices $\left(1650\right.$ and $\left.1558 \mathrm{~cm}^{-1}\right)$ and that the aggregated $\beta$-strands (between 1630 and $1620 \mathrm{~cm}^{-1}$ ) are formed. 


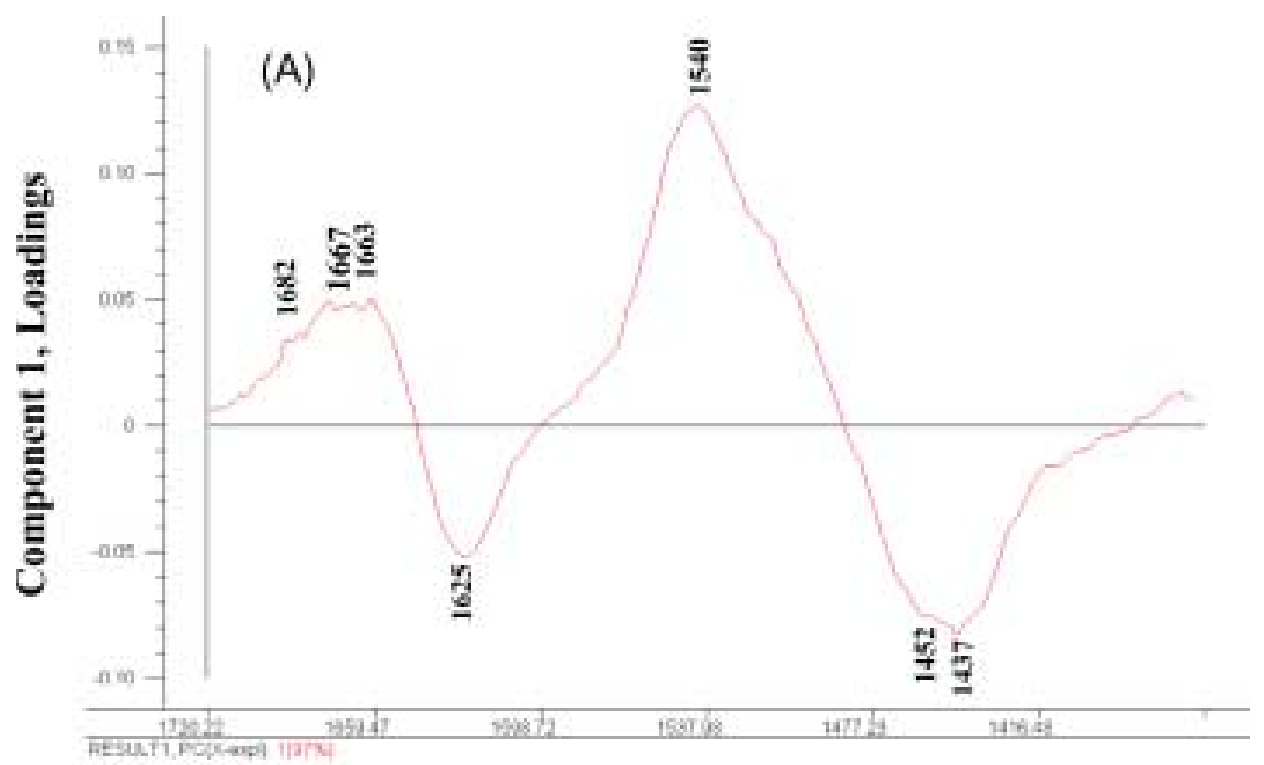

\section{Wavenumber $/ \mathrm{cm}^{-1}$}

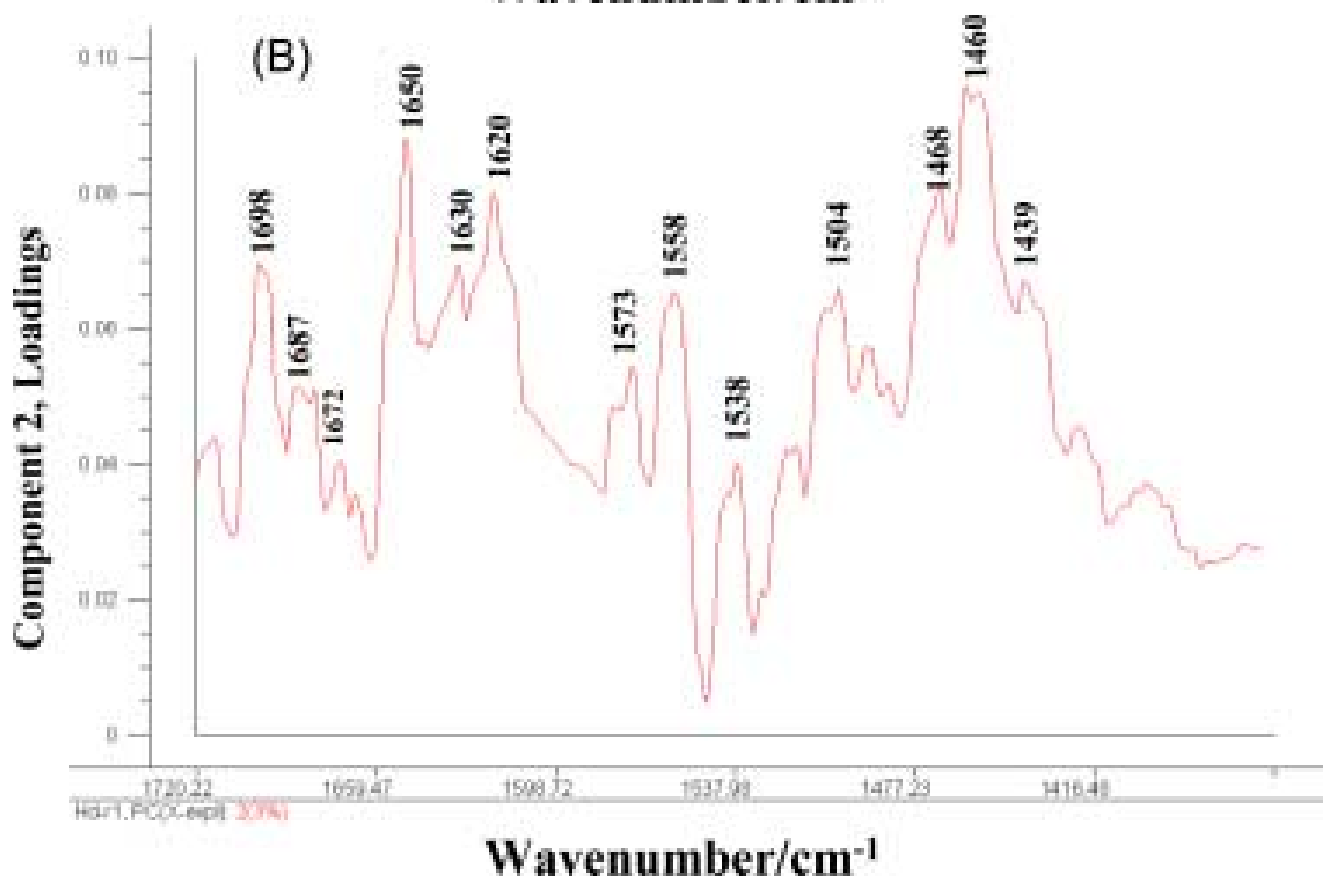

Fig. 16. Loading plots of PC1 (A) and PC2 (B) for the score plot in Fig. 15. (Reproduced from [35] with permission. (C)2001, American Chemical Society.)

\subsection{D IR correlation spectroscopy}

Figure 17 shows the (A) synchronous and (B) asynchronous correlation maps of HSA for the rapidly exchange amide protons, which are constructed from the five spectra in Group I (in Fig. 15). The power spectrum along the diagonal line of the synchronous spectrum shown in Fig. 18 (I) reveals that the 


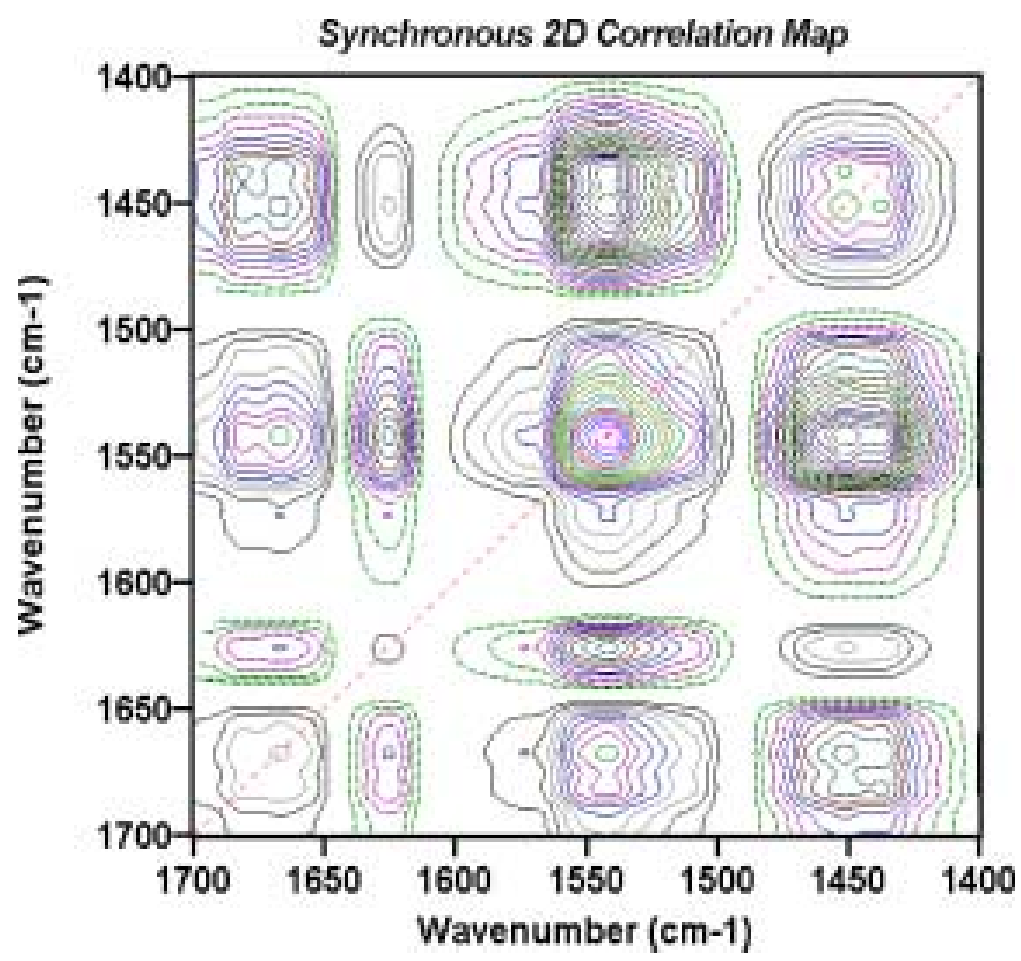

(A)

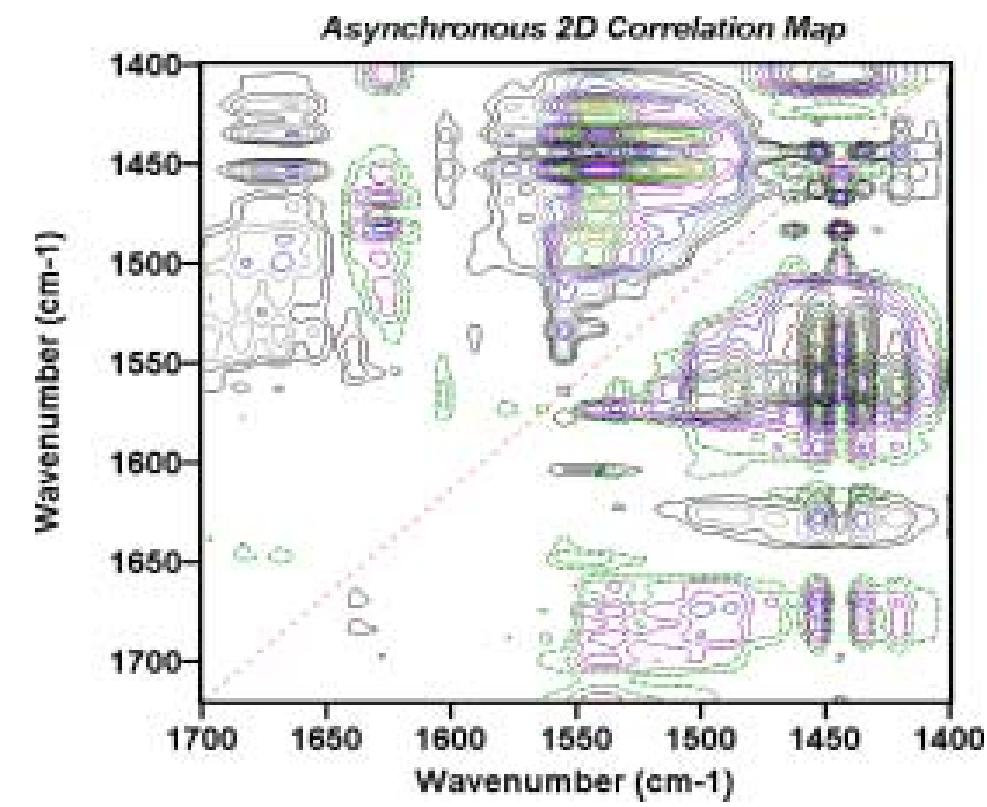

(B)

Fig. 17. (A) Synchronous and (B) asynchronous 2D IR correlation spectra of HSA calculated from five spectra (Group I), which measured between 1.83 and $5.30 \mathrm{~min}$ after the initiation of the H/D exchange. (Reproduced from [35] with permission. (C) 2001, American Chemical Society.) 


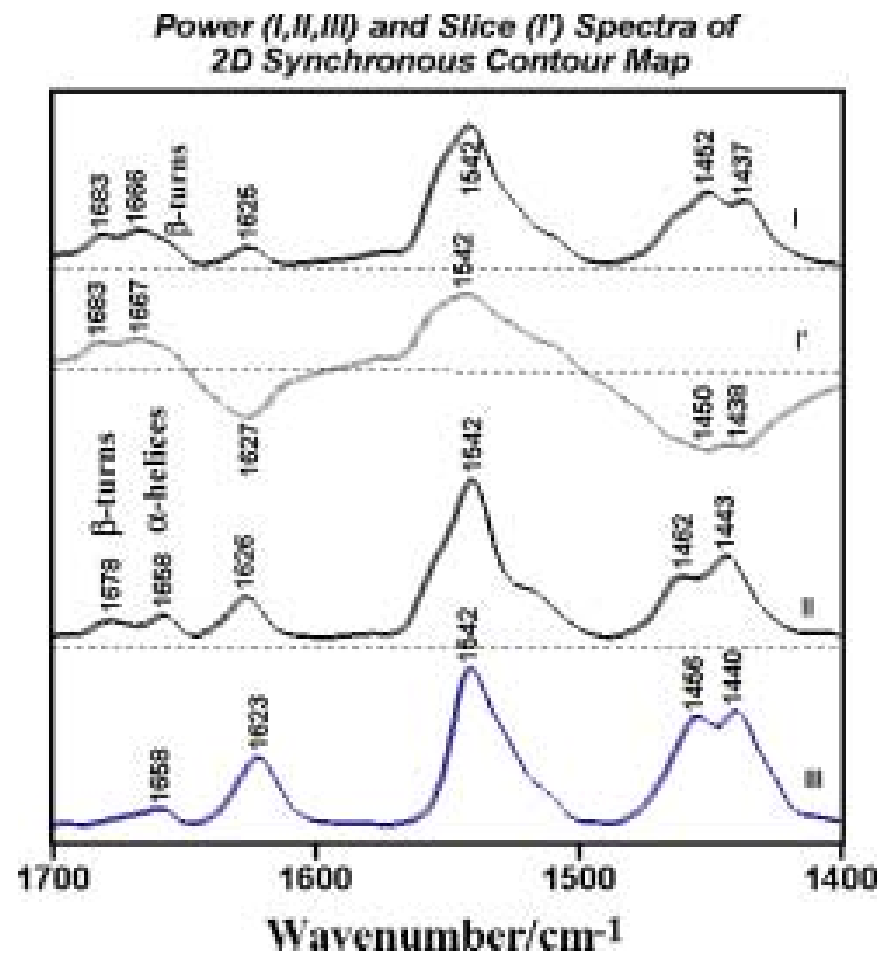

Fig. 18. Power spectra extracted from the synchronous 2D contour maps; (I) from Fig. 17(A), Group I, (II) from Fig. 20(A), Group II, and (III) from Group III. (I') Slice spectra at $1667 \mathrm{~cm}^{-1}$ extracted from the synchronous 2D contour maps shown in Fig. 17(A). (Reproduced from [35] with permission. (C)2001, American Chemical Society.)

synchronous map is characterized by autopeaks at 1683,1666 , and $1625 \mathrm{~cm}^{-1}$ in the amide I region, that at $1542 \mathrm{~cm}^{-1}$ in the amide II region, and those at 1452 and $1437 \mathrm{~cm}^{-1}$ in the amide II' region. The appearance of these autopeaks mean that the intensities of these amide bands change significantly with the progress of the H/D exchange. The amide I bands at 1683 and $1666 \mathrm{~cm}^{-1}$ are due to the $\beta$-turn structures. Therefore, it seems that the amide groups associated with the $\beta$-turn structures are involved in the first H/D exchange during the deuteration process.

It is noted that the slice spectrum at $1666 \mathrm{~cm}^{-1}$ extracted from the synchronous spectrum in Fig. 17(A) (Fig. $18\left(\mathrm{I}^{\prime}\right)$ ) is very similar to the loadings plot for PC1 in Fig. 16(A). The results of the 2D correlation analysis and PCA are in a very good agreement [35].

The asynchronous spectrum (Fig. 17(B)) looks complicated, but the deconvoluted peak positions in the asynchronous spectrum are in a good agreement with those in the second derivative spectra [35]. A slice spectrum extracted at $1543 \mathrm{~cm}^{-1}$ from the asynchronous spectrum is shown in Fig. 19(I). The slice spectrum develops four new bands at $1655,1640,1613$ and $1604 \mathrm{~cm}^{-1}$ in the amide I region, assigned to $\alpha$-helices $\left(1655 \mathrm{~cm}^{-1}\right)$, intramolecular $\beta$-strands or random coil $\left(1640 \mathrm{~cm}^{-1}\right)$, and side chains (1613 and $1604 \mathrm{~cm}^{-1}$ ), respectively. In fact, the H/D exchanges in the side chains should occur very fast according to the proposed two crucial inhibition factor for the H/D exchange in native proteins. The asynchronous map allows one to explore the order in the H/D exchange of secondary structure elements. The asynchronous spectrum shows cross peaks at $(1640,1669)$ and $(1640,1685) \mathrm{cm}^{-1}$ in the amide I region. However, no asynchronous cross peak is developed among the bands at 1685, 1669, and $1625 \mathrm{~cm}^{-1}$, suggesting that the secondary structures giving the peaks at 1685,1669 , and $1625 \mathrm{~cm}^{-1}$ show 


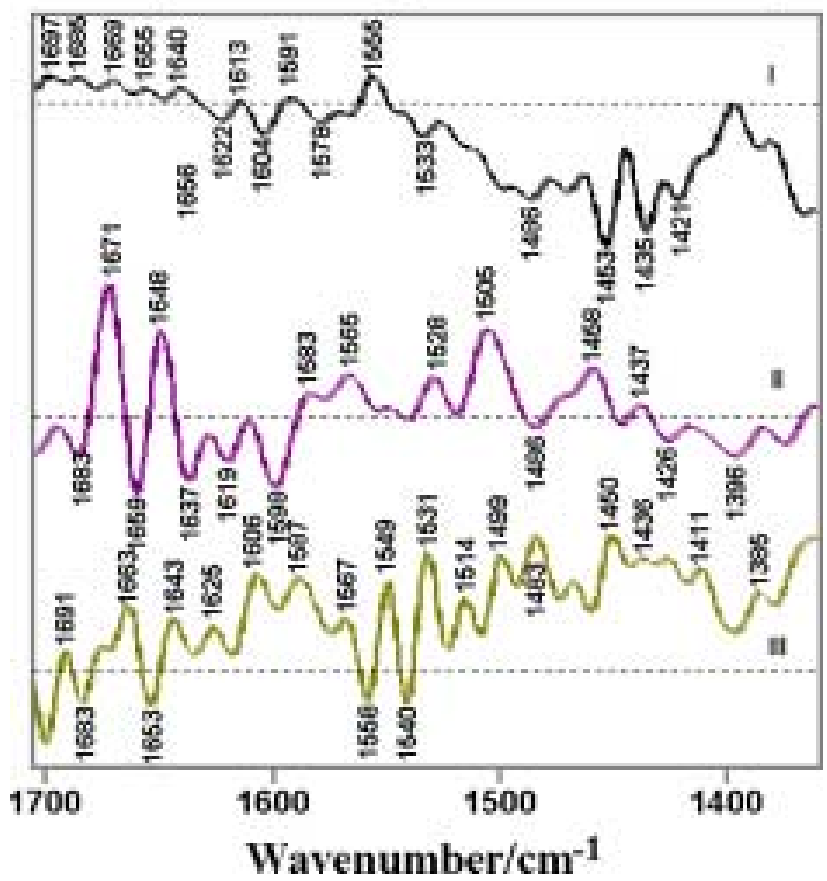

Fig. 19. Slice spectra at $1543 \mathrm{~cm}^{-1}$ extracted from the asynchronous 2D contour maps; (I) from Fig. 17(B), Group I, (II) from Fig. 20(B), Group II, and (III) from Group III. (Reproduced from [35] with permission. (C)2001, American Chemical Society.)

very similar or almost equal H/D exchange kinetics. In contrast, it seems that the secondary structure that has the band at $1640 \mathrm{~cm}^{-1}$ shows quite different behavior in the H/D exchange from those with the amide I band at 1685 and $1669 \mathrm{~cm}^{-1}$. The signs of cross peaks at $(1640,1669)$ and $(1640,1685) \mathrm{cm}^{-1}$ suggest that the H/D exchange occurs in the $\beta$-strands $\left(1640 \mathrm{~cm}^{-1}\right)$ earlier than in the $\beta$-turn structures $(1685$ and $1669 \mathrm{~cm}^{-1}$ ).

Figure 20 shows the (A) synchronous and (B) asynchronous correlation maps of HSA calculated from nine IR spectra (spectra from HD07 to HD16, Group II in Fig. 15) measured between 6.4 and 13.4 min after the initiation of the H/D exchange. The power spectrum and the slice spectrum extracted from the synchronous and asynchronous spectra in Fig. 20(A) and (B) are shown in Fig. 18 (II) and 19 (II), respectively. The most notable difference between the synchronous spectra in Fig. 17(A) and Fig. 20(A) is the appearance of an autopeak near $1658 \mathrm{~cm}^{-1}$ in Fig. 18 (II). This band obviously arises from the $\alpha$-helix structure. This observation reveals that besides the H/D exchanges in the $\beta$-turns $\left(1678 \mathrm{~cm}^{-1}\right)$, the $\mathrm{D}_{2} \mathrm{O}$ molecules start going into the accessible parts of $\alpha$-helices in the second time domain of the $\mathrm{H} / \mathrm{D}$ exchange.

The asynchronous spectrum develops cross peaks at $(1671,1683),(1653,1671),(1653,1683),(1623$, $1671)$, and $(1623,1653) \mathrm{cm}^{-1}$ in the amide I region. The signs of the cross peaks suggest the following sequences of the H/D exchanges in the amide protons.

$$
\begin{aligned}
& \beta \text {-turns }\left(1683 \mathrm{~cm}^{-1}\right) \rightarrow \text { aggregated } \beta \text {-strands }\left(1623 \mathrm{~cm}^{-1}\right) \rightarrow \\
& \beta \text {-turns }\left(1671 \mathrm{~cm}^{-1}\right) \rightarrow 1653 \mathrm{~cm}^{-1}(\alpha \text {-helices }) .
\end{aligned}
$$




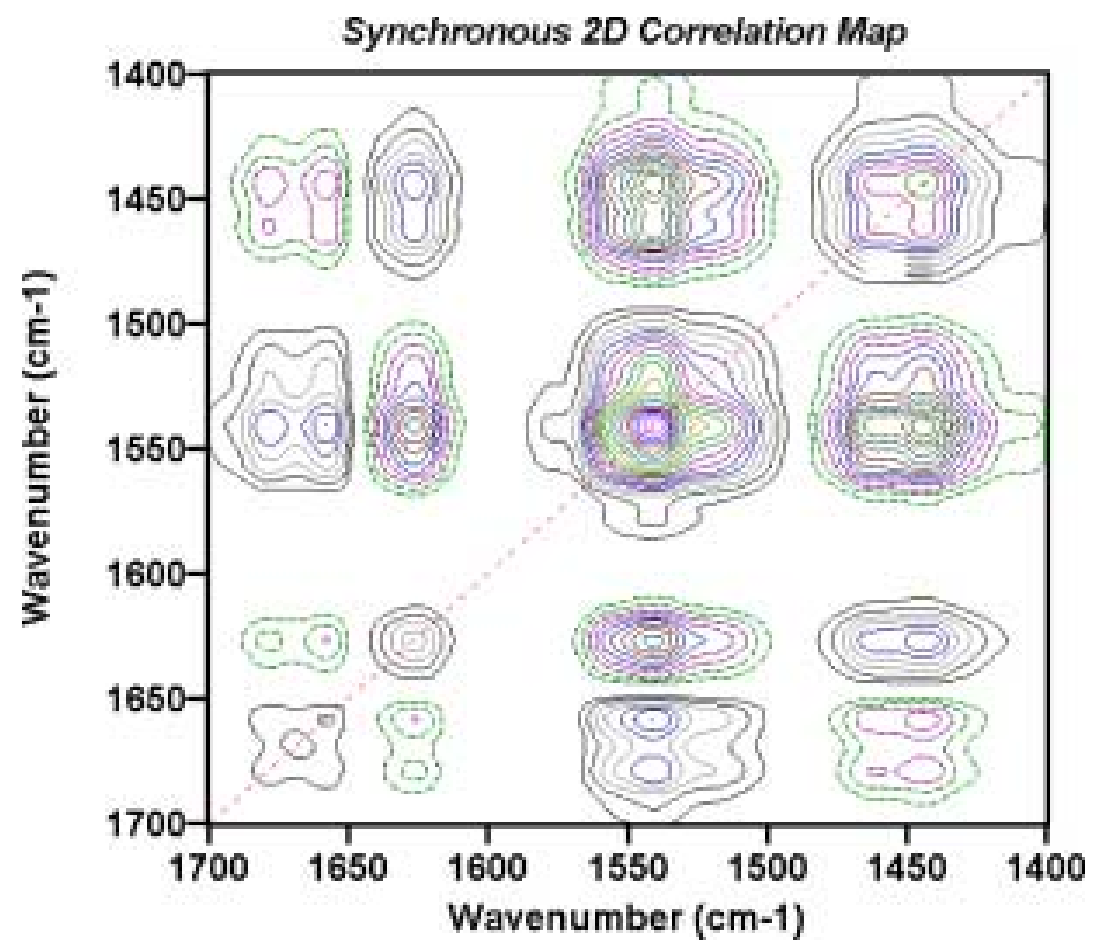

(A)

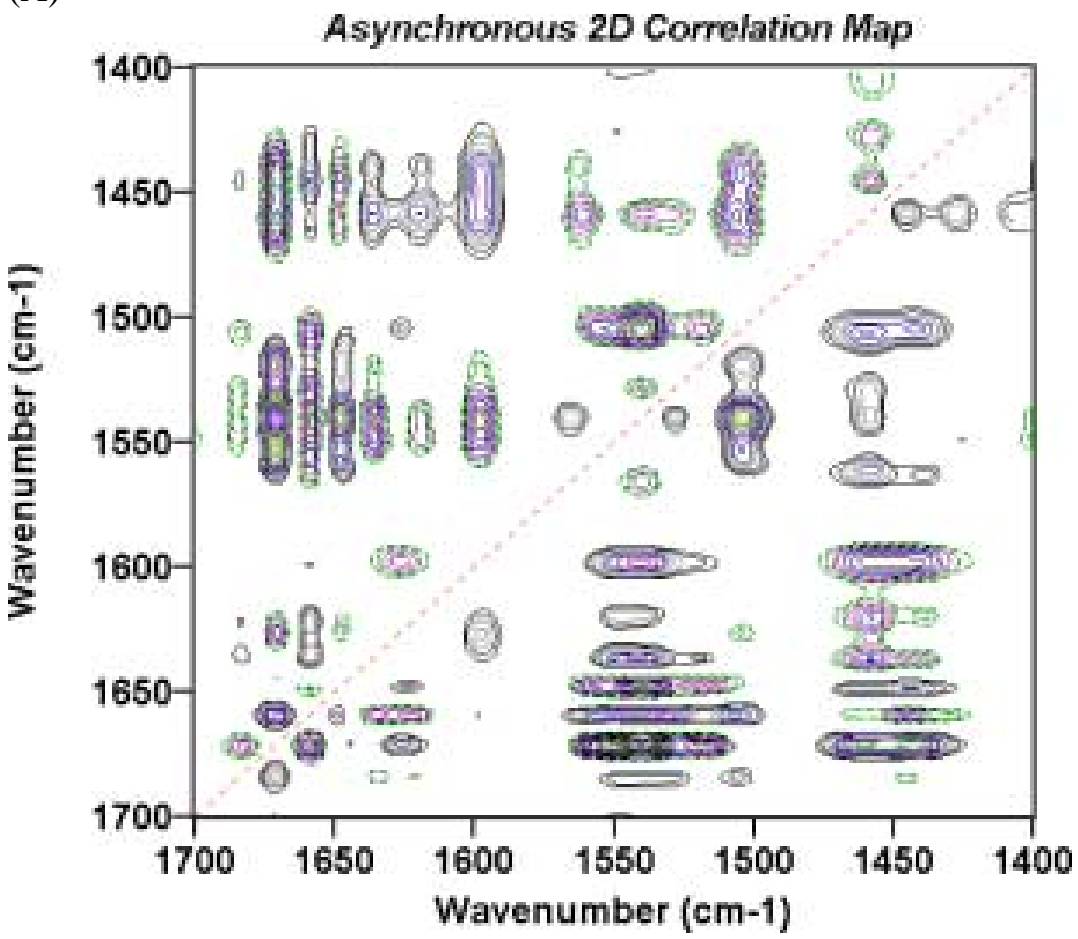

(B)

Fig. 20. (A) Synchronous and (B) asynchronous 2D IR correlation spectra of HSA calculated from nine spectra (Group II) measured between 6.4 and 13.4 min after the initiation of the H/D exchange. (Reproduced from [35] with permission. (C) 2001, American Chemical Society.) 
Wu et al. [35] also investigated the (A) synchronous and (B) asynchronous correlation maps of HSA, constructed from the nine spectra measured between 25.2 to $181 \mathrm{~min}$ after the beginning of H/D exchange process (Group III). Fig. 18 (III) and Fig. 19 (III) show the power spectrum and the slice spectrum extracted from the synchronous and asynchronous spectra, respectively. It was found from the synchronous map that the exchanges in the $\alpha$-helices $\left(1656 \mathrm{~cm}^{-1}\right)$ and the formation of aggregated $\beta$-strands $\left(1623 \mathrm{~cm}^{-1}\right)$ dominate in this time domain.

The sequence order of $\mathrm{H} / \mathrm{D}$ exchange revealed by the sign of the asynchronous cross peaks is summarized as follows;

$$
\begin{aligned}
& \beta \text {-turns }\left(1663 \mathrm{~cm}^{-1}\right) \rightarrow \beta \text {-turns }\left(1683 \mathrm{~cm}^{-1}\right), \text { random coil }\left(1643,1540 \mathrm{~cm}^{-1}\right) \rightarrow \\
& \alpha \text {-helices }\left(1653,1549 \mathrm{~cm}^{-1}\right) \rightarrow \text { aggregated } \beta \text {-strand }\left(1623 \mathrm{~cm}^{-1}\right) .
\end{aligned}
$$

This study has demonstrated that 2D IR correlation spectroscopy study is powerful to explore the kinetics of the H/D exchanges in HSA and to unravel poorly resolved amide I, II, and II $^{\prime}$ regions. The combination of PCA and 2D correlation analysis turns out to be very efficient to distinguish the fast kinetics from the slow ones during the H/D exchange process.

\section{References}

[1] R.E. Hester and R.B. Girling, eds, Spectroscopy of Biological Molecules, Royal Society of Chemistry, London, 1991.

[2] H.H. Mantsch and D. Chapman, eds, Infrared Spectroscopy of Biomolecules, Wiley, New York, 1996.

[3] S. Krimm and J. Bandekar, Adv. Protein Chem. 38 (1986), 181.

[4] H. Susi and D.M. Byler, Arch. Biochem. Biophys. 258 (1987), 465.

[5] W. Mantele, Trends Biochem. Sci. 18 (1993), 197.

[6] R.J.H. Clark and R.E. Hester, eds, Biomolecular Spectroscopy, Part A and Part B, Wiley, Chichester, 1993.

[7] F. Siebert, in: Infrared Spectroscopy of Biomolecules, H.H. Mantsch and D. Chapman, eds, Wiley, New York, 1996, p. 83.

[8] M. Jackson and H.H. Mantsch, in: Infrared Spectroscopy of Biomolecules, H.H. Mantsch and D. Chapman, eds, Wiley, New York, 1996, p. 311.

[9] M. Jackson and H.H. Mantsch, Critical Rev. Biochem. Mol. Biol. 30 (1995), 95.

[10] H. Torii and M. Tasumi, in: Infrared Spectroscopy of Biomolecules, H.H. Mantsch and D. Chapman, eds, Wiley, New York, 1996, p. 239.

[11] P.I. Haris and D. Chapman, in: Infrared Spectroscopy of Biomolecules, H.H. Mantsch and D. Chapman, eds, Wiley, New York, 1996, p. 239.

[12] H. Fabian and W. Mantele, in: Handbook of Vibrational Spectroscopy, J.M. Chalmers and P.R. Griffiths, eds, Vol. 3, Willy, Chichester, 2001, p. 3399.

[13] J.M. Hadden, M. Bloemendal, P.I. Haris, I.H.M. Stokkum, D. Chapman and S.K.S. Srai, FEBS Lett. 350 (1994), 235.

[14] H. Kandori, Biochim. Biophys. Acta. 1460 (2000), 177.

[15] M. Nara, M. Tasumi, M. Tanokura, T. Hiroaki, M. Yazawa and A. Tsutsumi, FEBS Lett. 349 (1994), 84.

[16] M. Mizuguchi, M. Nara, K. Kawano and K. Nitta, FEBS Lett. 417 (1997), 153.

[17] I. Noda, Appl. Spectrosc. 47 (1993), 550.

[18] I. Noda, Appl. Spectrosc. 54 (2000), 994.

[19] Y. Ozaki and I. Noda, eds, Two-Dimensional Correlation Spectroscopy, AIP Conference Proceedings, Vol. 503, American Institute of Physics, New York, 2000.

[20] Y. Ozaki, in: Handbook of Vibrational Spectroscopy, J.M. Chalmers and P.R. Griffiths, eds, Vol. 3, Wiley, Chichester, 2001, p. 2135.

[21] I. Noda, A.E. Dowrey, C. Marcott, G.M. Story and Y. Ozaki, Appl. Sprectrosc. 54 (2000), 236A.

[22] I. Noda, in: Modern Polymer Spectroscopy, G. Zerbi, ed., Willey-VCH, Weinheim, 1999, p. 1.

[23] I. Noda, in: Handbook of Vibrational Spectroscopy, J.M. Chalmers and P.R. Griffiths, eds, Vol. 3, Wiley, Chichester, 2001, p. 2123.

[24] Y. Wu and Y. Ozaki, J. Infrared Millimeter Waves, in press.

[25] Y. Ozaki and I. Noda, in: Encyclopedia of Analytical Chemistry, R.A. Meyers, ed., Wiley, Chichester, 2000, p. 322.

[26] A. Nabet and M. Pezolet, Appl. Spectrosc. 51 (1997), 466. 
[27] N.L. Sefara, N.P. Magtoto and H.H. Richardson, Appl. Spectrosc. 51 (2000), 536.

[28] H.H. Richardson, N.L. Sefara, N.P. Magtoto and M.L. Caldwell, in Ref. 19, p. 173

[29] L. Smeller, P. Rubens, J. Frank, J. Fidy and K. Heremans, Vib. Spectrosc. 22 (2000), 119.

[30] L. Smeller and K. Heremans, Vib. Spectrosc. 19 (1999), 375.

[31] W. Dzwolak, M. Kato, A. Shimizu and Y. Taniguchi, Appl. Spectrosc. 54 (2000), 963.

[32] M.-J. Paquet, M. Auger and M. Pezolet, in Ref. 19, p. 103.

[33] B. Czarnik-Matusewicz, K. Murayama, Y. Wu and Y. Ozaki, J. Phys. Chem. B 104 (2000), 7803.

[34] K. Murayama, Y. Wu, B. Czarnik-Matusewicz and Y. Ozaki, J. Phys. Chem. B 105 (2001), 4763

[35] Y. Wu, K. Murayama and Y. Ozaki, J. Phys. Chem. B 105 (2001), 6251.

[36] C.P. Schultz, H. Fabian and H.H. Mantsch, Biospectrosc. 4 (1998), 19.

[37] F. Ismoya, Y. Wang and A.A. Ismail, Apl. Spectrosc. 54 (2000), 931.

[38] M. Sonoyama and T. Nakano, Appl. Spectrosc. 54 (2000), 968.

[39] P. Pencoska, J. Kubelka and T.A. Keiderling, Appl. Spectrosc. 53 (1999), 655.

[40] M. Muler, R. Buchet and U.P. Fringeli, J. Phys. Chem. 100 (1996), 10810.

[41] G. Panick, R. Malessa and R. Winter, Biochemistry 38 (1999), 6512.

[42] A.F. Allain, P. Paquin and M. Subirade, Int. J. Biol. Macromol. 26 (1999), 337.

[43] X.L. Qi, S. Brownlow, C. Holt and P. Sellers, Biochim. Biophys. Acta 1248 (1995), 43.

[44] T. Peters, Jr, All About Albumin, Biochemistry, Genetics, and Medical Applications, Academic Press, New York, 1994, p. 35 .

[45] J.R. Brown, in: Albumin; Structure, Function and Uses, V.M. Rosenoer, M. Oraz and M.A. Rotshild, eds, Pergamon Press, Oxford, 1977, p. 27.

[46] S. Era and M. Sogami, J. Pept. Res. 52 (1998), 431.

[47] Structure Explore - 1A06. Protein Data Bank, Department of Chemistry, Brookhaven National Laboratory, Upton, NY 11973, USD (http://www.rcsb.org/pdb).

[48] M. Dockal, D.C. Carter and F. Ruker, J. Biol. Chem. 274 (1999), 29303. 


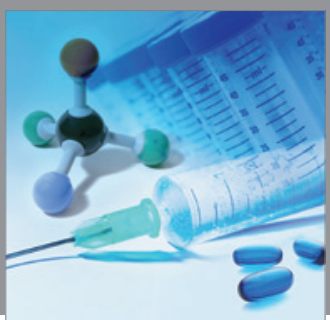

International Journal of

Medicinal Chemistry

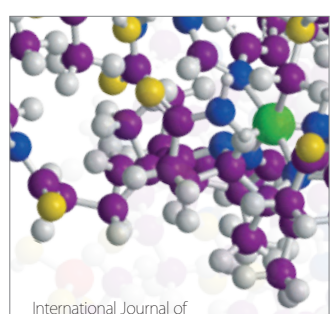

Carbohydrate Chemistry

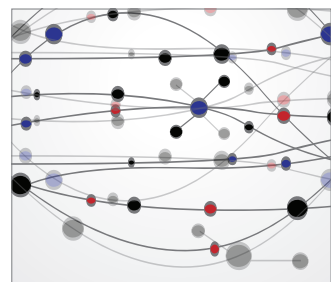

The Scientific World Journal
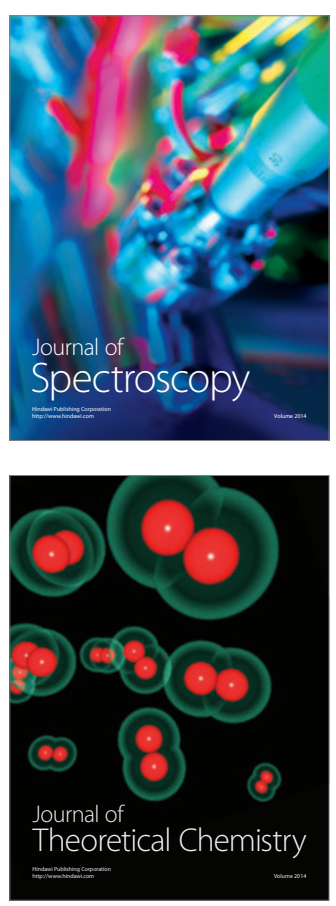
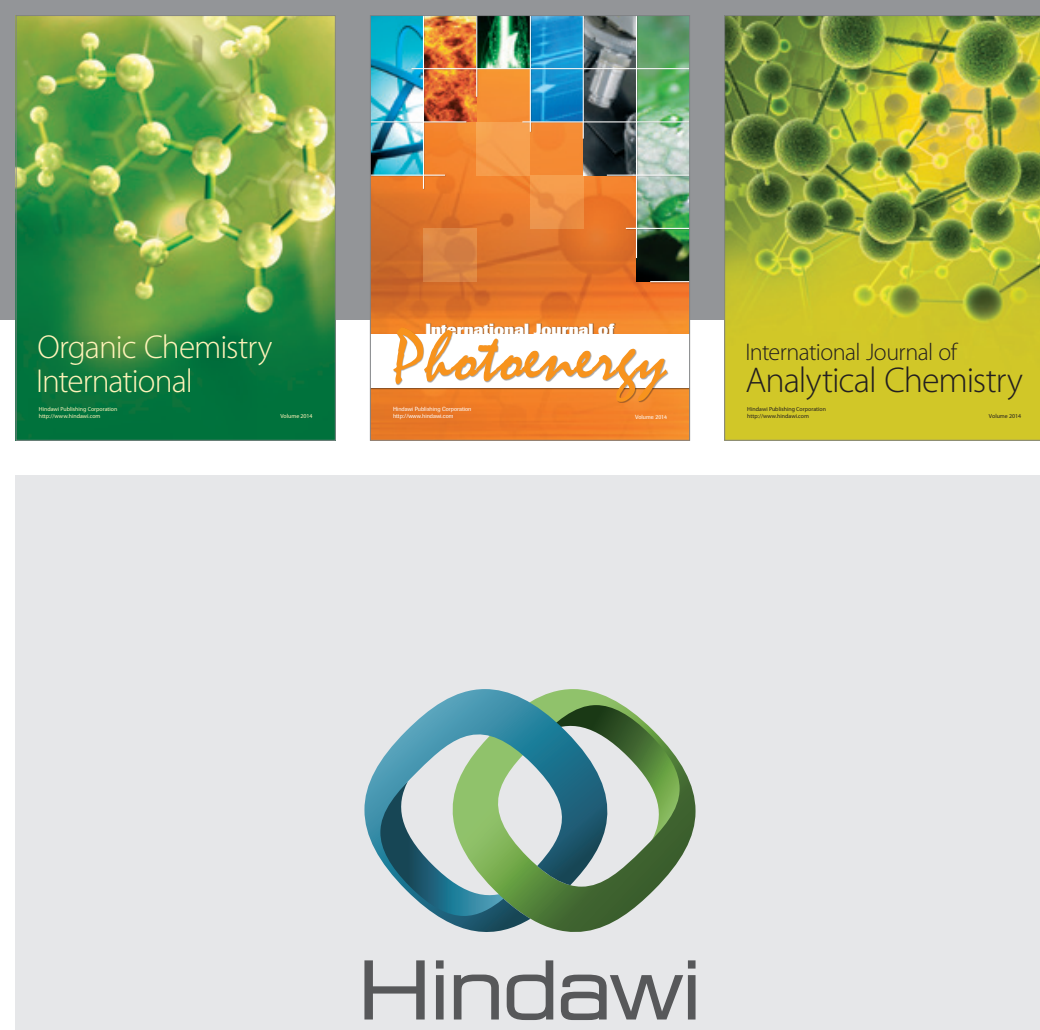

Submit your manuscripts at

http://www.hindawi.com
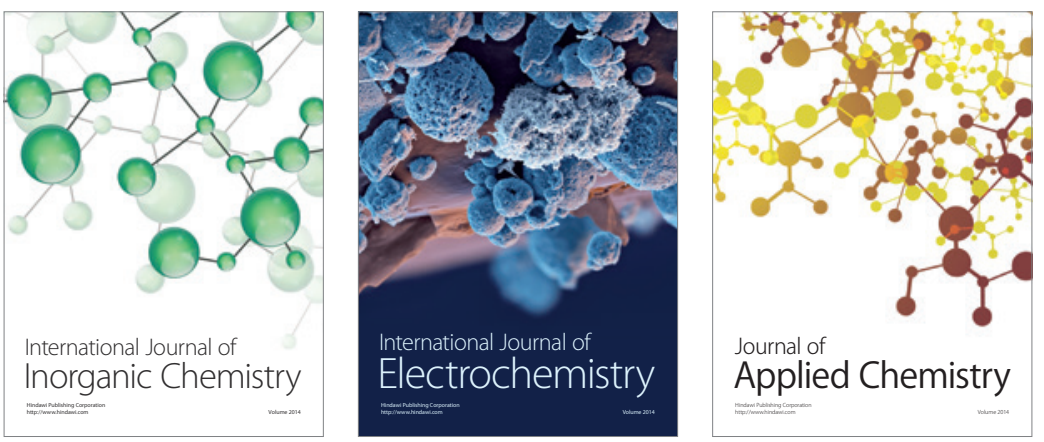

Journal of

Applied Chemistry
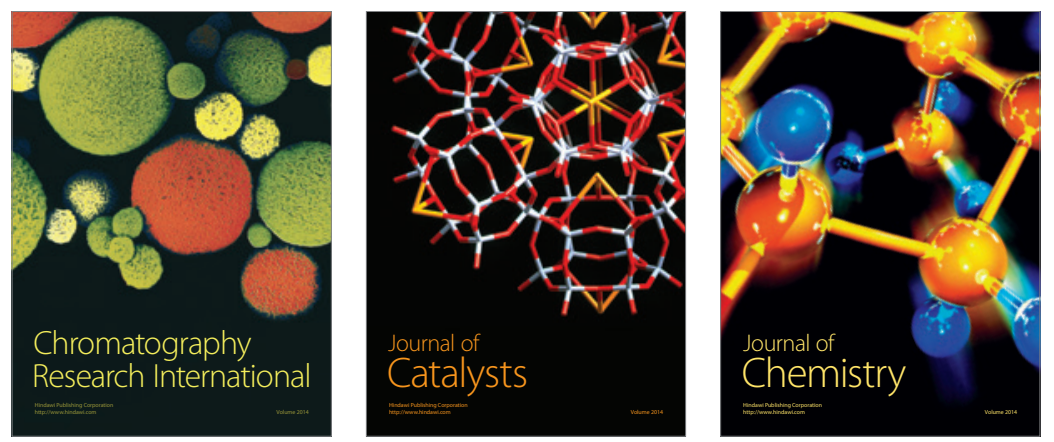
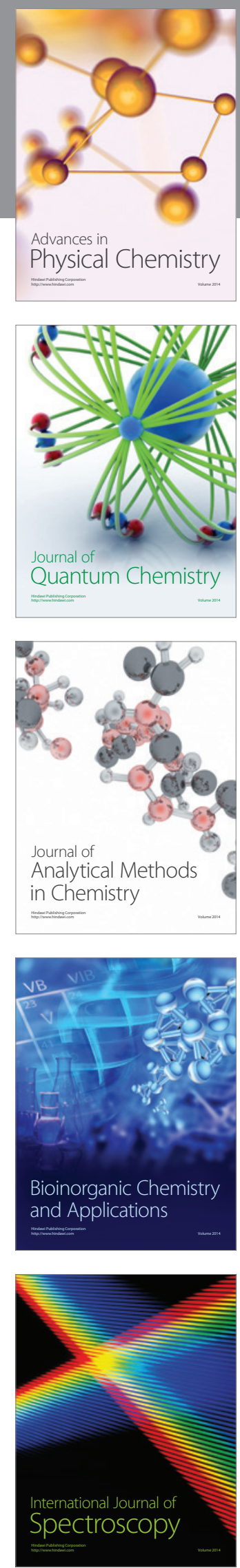